\title{
A Route to Sustainable Aviation: A Roadmap for the Realization of Aircraft Components with Electrical and Structural Multifunctionality.
}

\author{
Catherine E. Jones, Member, IEEE, Patrick J. Norman, Graeme M. Burt, Member, IEEE, Callum Hill, \\ Giuliano Allegri, Jason Yon, Ian Hamerton, Richard S. Trask.
}

\begin{abstract}
Increased electrification of aircraft power systems has been widely presented as a route towards meeting environmental and emissions targets for aircraft performance, via more-electric aircraft and future hybrid-electric aircraft concepts. In parallel, the superior mechanical performance of carbon fibre reinforced polymer (CFRP) has resulted in its increasing use for aircraft structures. The relatively low electrical conductivity of CFRP compared to traditional aluminium structures and copper conductors, limits the use of structural CFRP structures as electrical elements, so separate systems are needed. This adds structural mass and volume to a system, negating some of the benefits of using CFRP.

Closer integration of the composite structure and electrical power system, with an ultimate goal of achieving components with multifunctionality (combined thermal, electrical and structural functionality), offers a route towards the lightweighting of these systems, thus supporting improvements in aircraft performance. This paper presents a roadmap to achieve this multifunctionality, supported by the combination of introducing definitions for different levels of multifunctionality, associated design thresholds and trades between the electrical power system and CFRP materials/structures. Existing multifunctional electricalthermal-structural CFRP-based solutions are contextualized within this roadmap. This enables realization of viable routes for developing multifunctional systems for the strategic focus of future research efforts.
\end{abstract}

Index Terms - aircraft electrification, aircraft electrical power systems, carbon fiber composites, multifunctional materials

\section{INTRODUCTION}

$\mathrm{T}$ HERE is a growing trend for the increased use of electrical power on aircraft to improve overall aircraft efficiency, reduce fuel burn and consequently, emissions of greenhouse gasses. This has led to the state-of-the-art (SOTA)

Manuscript submitted for review on $22^{\text {nd }}$ January 2021, and accepted for publication on $20^{\text {th }}$ April 2021.

This work was supported by the Rolls-Royce University Technology Centre for Electrical Power Systems at the University of Strathclyde and the RollsRoyce University Technology Centre for Composites at the University of Bristol, and the Engineering and Physical Sciences Research Council through the ACCIS Centre for Doctoral Training grant, no. EP/G036772/1,

Catherine E. Jones, Patrick J. Norman and Graeme M. Burt are with the Institute for Energy and Environment, Department of Electronic and Electrical Engineering, University of Strathclyde, Glasgow, G1 1XQ, U.K. (e-mail: more-electric aircraft (MEA) [1], and the future concept of hybrid electric propulsion aircraft [2]. In parallel to this, there has been a trend for the light-weighting of structures, via the use of non-metallic composite materials, in particular carbon fibre reinforced polymer (CFRP). More than $50 \%$ of the structure of a SOTA MEA, e.g. the Boeing 787, is made from CFRP. This reduces structural weight by $\sim 20 \%$ [3], and translates to a 10-12\% improvement in overall aircraft efficiency [4].

A number of different sub-systems (e.g. electrical power, thermal and structural) combine to provide different critical functionalities for an aircraft. Whilst these systems are often considered as separate entities, there are interdependencies between them. A possible route to optimizing a system with respect to weight and volume is to take a holistic and multidisciplinary approach to develop multifunctional (MF) components [5,6] such that a single component supports the functionality requirements of more than one system [5]. Integrating different functions in the current light-weight advanced material systems is a fundamental challenge, especially if those functions are mutually exclusive [7]. Understanding the function-structure relationships for MF will enable the next generation of applications in aerospace engineering.

For a metallic aircraft, the structure of the aircraft could be considered MF, since this material acts as a mechanical structure, current return pathway and provides electromagnetic (EM) shielding. The challenge for composite-based aircraft, is to identify viable routes to realizing MF components with combined electrical, structural and thermal functionality. MF capability is dependent on a combination of the physical limitations inherent to adapting materials to perform electrical and structural functions, the electrical requirements and topology of the on-board electrical power system (EPS) and the structural requirements of the component. The focus of this paper is primarily on electrical-structural functionality.

catherine.e.jones@Strath.ac.uk, patrick.norman@strath.ac.uk, Graeme.burt@strath.ac.uk). Callum Hill, Giuliano Allegri, Ian Hamerton and Richard S. Trask are with the Bristol Composites Institute, Department of Aerospace Engineering, University of Bristol, Bristol, BS8 ITR, U.K. Jason Yon is with the Electrical Energy Management Group, Department of Mechanical Engineering, University of Bristol, Bristol, BS8 1TR, U.K. (email: callum.hill@bristol.ac.uk, ian.hamerton@bristol.ac.uk, Giuliano.allegri@bristol.ac.uk, jason.yon.02@bristol.ac.uk). 
However, owing to heat losses associated with electrical conduction, thermal functionality must also be considered.

Compact systems, where an electrical system has been encased in CFRP, have been implemented in satellite applications, rated from a few Watts [8] to a few hundred Watts [9]. By embedding the electrical system in the CFRP structure, the need for cable harnesses is reduced. By developing compact electronics which fit into the CFRP housing, the combined system mass and volume are reduced. Flexible, polyimide connectors and printed circuit boards match the flexibility of the electrical system to that of the CFRP structure $[10,11]$. The honeycomb structure of the composite panel enables the integration of the energy storage system via thin film capacitors in the composite panel [9]. However, the EPS in this system does not have structural functionality.

To date, the development of CFRP with structural and electrical multifunctionality has focused on: (1) high frequency $(>\mathrm{MHz})$, very low power applications such as radio frequency antennae and waveguides, EM shielding, e.g. [12-14]; (2) adaption of CFRP to mitigate the high energy pulse of lightning strike, e.g. [15]; and, (3) use of CFRP as a high frequency ground plane with metallic low frequency ground rails laid over CFRP [16-18]. Limited studies on the low frequency response of CFRP to electrical fault current, and resulting choices of grounding topology are discussed in [19], but the use of CFRP for the low frequency ground rails is not explored. As noted in [20], a major challenge for low frequency conduction of electrical current is the low electrical conductivity of CFRP.

To progress the limited nature of the existing MF and integrated solutions for electrical-structural systems, it is necessary to identify viable routes to develop these systems for the MEA. By considering the requirements of the EPS, combined with existing electrification of composites landscape and the technical challenges which must be overcome, a road map for the development of MF components is created.

The remainder of this paper is structured as follows: Section II will consider the key trends of MEA architectures, key requirements of MF CFRP are captured and categories for level of MF (LoMF) defined. Section III maps the literature landscape for MF composites with combined electrical and structural functionality, capturing what may be transferable to aerospace applications, identifying major challenges and routes to overcome these. Section IV identifies the key design thresholds for the EPS MF composite design space, leading to the presentation of a road map for the development of high technology readiness level (TRL) MF composites for an aircraft EPS, and identification of viable routes forwards in Section V. Conclusions are presented in Section VI.

\section{REQUIREMENTS OF MF SYSTEMS FOR AIRCRAFT ELECTRICAL POWER SYSTEMS}

\section{A. MEA Electrical Power Systems Overview}

Fig. 1 shows one channel of a dual channel EPS for an example SOTA MEA EPS, this is based on published information for the EPS on the Boeing 787 [1, 21-22]. The electrical power rating of a SOTA MEA EPS (Boeing 787) is $\sim 1.5 \mathrm{MW}$. This indicates the wide variety of voltage and power levels, power conversion stages, energy sources and loads in a SOTA MEA,

In Fig. 1 the main $\mathrm{AC}$ distribution bus is run at constant voltage $\left(230 \mathrm{~V}_{\text {rms }}\right)$, variable frequency $(\sim 300-800 \mathrm{~Hz})$ to match frequency engine speed [1]. Electrical power is converted to +/$270 \mathrm{~V}_{\mathrm{DC}}$ using an auto-transformer rectifier unit (ATRU). DC distribution has been proposed as an alternative approach for future MEA power systems [21-22], due to the applicability of diode bridge rectifiers to $270 \mathrm{~V}_{\mathrm{DC}}$, and reduced weight due to fewer power conversion stages [22]. In Fig. 1 a motor control unit (MCU) converts power for motor loads, such as the environmental conditioning system (ECS) motor, and a buckboost unit (BBU) converts power between $+/-270 V_{D C}$ and 28 $\mathrm{V}_{\mathrm{DC}}$. A transformer rectifier unit (TRU) converts the $230 \mathrm{~V}_{\mathrm{rms}}$ to $28 \mathrm{~V}_{\mathrm{DC}}$. The TRU provides galvanic isolation between the $\mathrm{AC}$ and low power DC current return path. An AC-AC converter provides $115 \mathrm{~V}_{\mathrm{rms}}$ at $400 \mathrm{~Hz}$ [22]. Batteries on the $28 \mathrm{Vdc}$ bus provide power for electric start of the APU and additional power for avionic loads. For example, on the Boeing 787 aircraft, the batteries are lithium-ion, with a specific energy density of $135 \mathrm{Wh} / \mathrm{kg}$, and specific power density of $2 \mathrm{~kW} / \mathrm{kg}$ [23]. The switching frequency of power electronics is $10 \mathrm{~s}$ of $\mathrm{kHz}$ [24], to minimize filter size.

The generators, including the auxiliary power unit (APU), are wound field synchronous generators and motor loads are high speed permanent magnet synchronous machines [21]. Aside from the environmental control system (ECS), other loads include electromechanical actuators $(2-40 \mathrm{~kW})$, fuel pumps (200 kVA total), wings ice protection systems (WIPS) (up to $200 \mathrm{~kW}$ [21]), galley loads and avionics. The lower power loads connected to the EPS shown in Fig. 1 form a secondary power distribution system, which is used to distribute power to loads with a current demand of less than 15 A [25]. Solid state power controllers (SSPCs) provide both connection and protection functionality in this section of the network. The wider EPS (primary and secondary) will include other protection devices, such as circuit breakers, which are not detailed in Fig. 1, but are fundamental to the safe operation of the EPS.

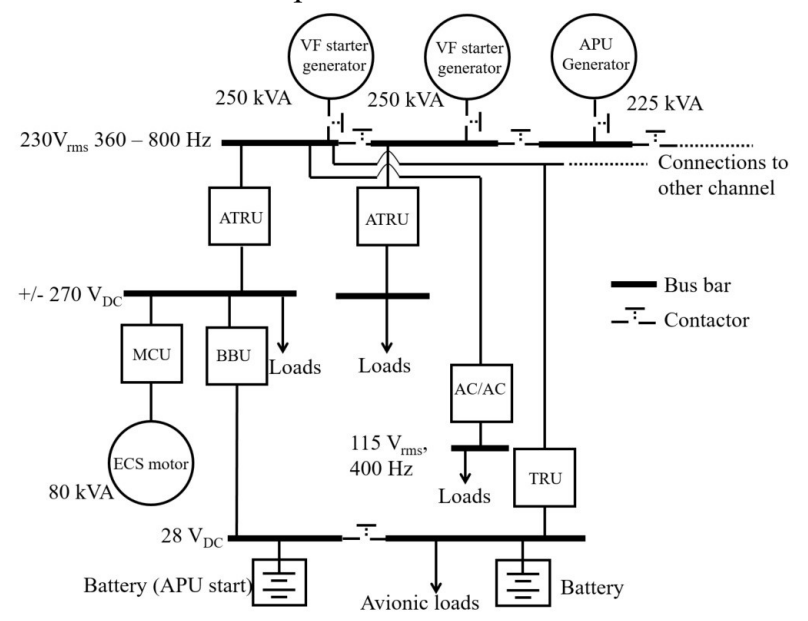

Fig. 1: Example EPS architecture for one channel of a dual channel, SOTA MEA (e.g. B787) 


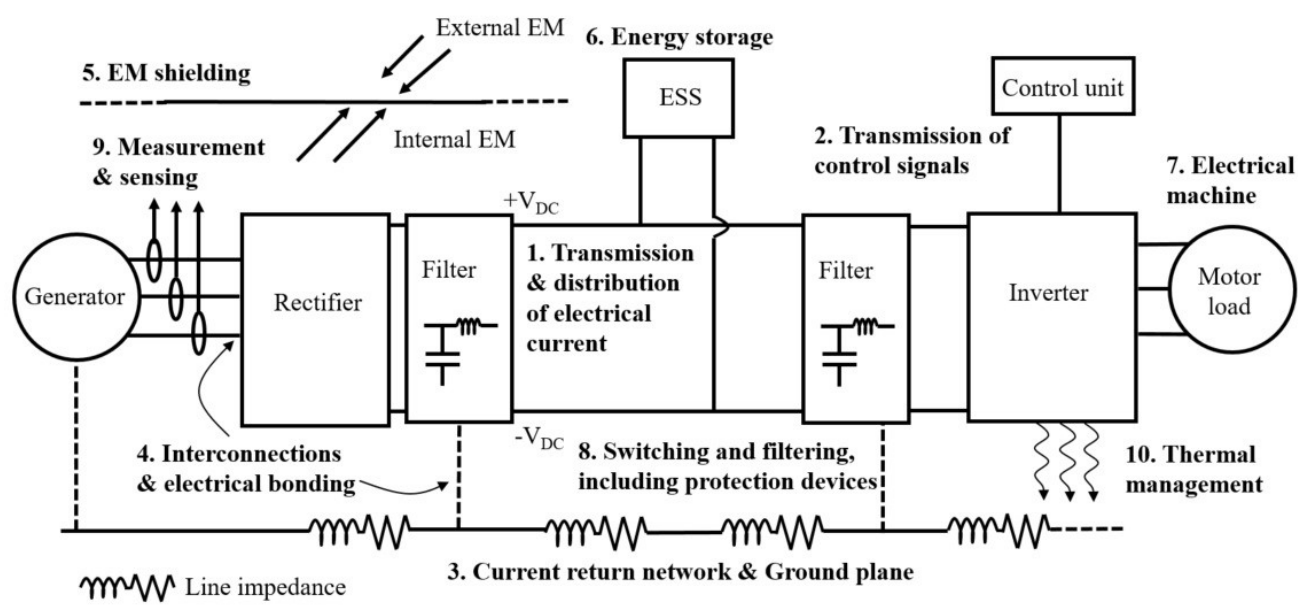

Fig. 2: identified areas for combined electrical-thermal-structural multifunctionality.

The EPS is grounded using a TN-C-S topology: a 4-wire system, with a solidly grounded neutral point [25]. AC and DC ground paths must be kept separate [26,27]. The low electrical conductivity of CFRP necessitates that the electrical and composite structural systems are kept physically separate. On SOTA composite aircraft, a current return network has been designed to avoid electrical current passing through CFRP structures e.g. [28].

\section{$B$. Identification of levels of MF for the MEA EPS}

In order to map out a route for MF systems which incorporates an EPS architecture, the electrical functionality that is required of the CFRP based structure must be identified. Fig. 2 indicates the ten key areas of electrical functionality for integration of electrical power systems with composites which have been identified (the numbers correspond to numbering in Fig. 2):

1) CFRP with electrically conductive pathways for the transmission and distribution of electrical current for a section of the EPS

2) Transmission of low power control signals

3) A current return network and ground plane, including conduction of fault current and common mode currents.

4) Methods of electrically interconnecting and bonding an electrical system to CFRP.

5) EM shielding both for external EM, shielding of cables and preventing transmission of EM from equipment.

6) CFRP forming a structural energy storage system.

7) Non-metallic, composite elements of an electrical machine such as machine winding (stator and rotor), rotor banding or containment sleeve.

8) CFRP having the functionality to condition the electrical current: e.g. a filter or switching of current, including power electronics, SSPCs and protection devices such as circuit breakers.

9) Methods for measurement and sensing of the currents and voltages conducted through CFRP are needed for monitoring and control.

10) Thermal functionality of CFRP for thermal management.

These areas of functionality operate at a range of power levels. By inspection of Fig. 1 and Fig. 2, four broad power levels can be identified: very low power (up to a few Watts) for high frequency ( $\mathrm{GHz}$ and above) EM applications, low power for control signals and power to the control system (3 -15 $\mathrm{V}_{\mathrm{DC}}$, $10 \mathrm{~s}$ of Watts), medium power systems (28 V, 100s of Watts) and high power (up to $540 \mathrm{~V}_{\mathrm{DC}}, 1000 \mathrm{~s}$ of Watts).

The degree of MF of the CFRP structure, has been categorized for this paper into three broad Levels of MF (LoMF). These are illustrated in Fig.3. At LoMF1, the electrical system is

integrated with the CFRP, but only conducts electrical current if there is a ground fault through CFRP. At LoMF2 electrical current is conducted through a MF pathway. At LoMF3 the pathway actively conditions the electrical current.

At LoMF1 the CFRP has limited MF capability and is used to encase a section of the EPS equipment with minimal use of cable harnesses and raceway, e.g. [8-11,29]. At LoMF1, fault current may flow through CFRP during a ground fault (as investigated in [20]), but under normal circumstances the low frequency $(<\mathrm{GHz})$ electrical and structural functionality are decoupled. EMI shielding is provided on the outside of the CFRP casing. A total shielding effectiveness (SE) of $\sim 30 \mathrm{~dB}$ is required [30]. The dominant mechanisms of $\mathrm{SE}$ are reflection and absorption [31]. Shielding via reflection requires the material to have sufficient electrical conductivity, $\sim 10 \mathrm{~S} / \mathrm{m}$ or higher [33]. CFRP with a $35 \mathrm{wt} \%$ epoxy resin, and thickness of $3 \mathrm{~mm}$, has an EMI SE of $30 \mathrm{~dB}$ [32]. Typical composites have a higher CF loading than $33 \%$, and therefore should have a higher EMI SE.

At LoMF1, a low frequency ground plane is provided either by metallic ground rails over the CFRP casing [17], or the use of a copper mesh [29]. A high frequency ground plane is provided by the CFRP. Whilst the low frequency electrical system has no structural functionality at LoMF1, the integrated electrical components must have flexibility to match that of the CFRP structure. For example, this is demonstrated in $[8,11]$ via the use of flexible circuit boards and polyimide connectors. A challenge to embedding cables (LoMF 1) and MF electrically conductive pathways through CFRP (LoMF 2 and 3) are the thermal requirements associated with higher power levels. If the resin matrix is heated and the temperature reached approaches the glass transition temperature $\left(T_{g}\right)$ of the resin matrix, then the resin will soften and the composite will lose structural continuity (i.e. creep when subjected to a tensile load or progressively buckle when loaded in compression). At 
This is a pre-print of paper TTE-Reg-2021-01-0074 which was accepted for publication in IEEE Trans. On Transportation Electrification on $20^{\text {th }}$ April 2021, and as such is subject to IEEE copyright.

temperatures above $T_{g}$, the resin matrix loses its inherent rigidity, thereby losing structural mechanical strength and stiffness [34]. If the CFRP is heated above $T_{g}$ to the decomposition temperature, $T_{d e c}$, then the chemical bonds within the polymer resin start to break. The values of $T_{g}$ depend on the type of resin matrix. Typical values of $T_{g}$ for epoxy resin are $\sim 100-200{ }^{\circ} \mathrm{C}[35,36]$, with $T_{d e c}$ significantly higher at $\sim 300-400{ }^{\circ} \mathrm{C}[37]$. Furthermore, differences in coefficients of thermal expansion (CTE) between different materials may lead to stress concentrations and promote mechanical degradation.

Electrical functionality at all levels of MF is underpinned by electrical and thermal models of CFRP at a macro (component) scale, to enable integration with system and subsystem level models of an EPS. There are limited macroscale models of CFRP in the published literature. Examples include [20,38-40]. There is a need for development of hierarchical models to fully represent MF composites. Macroscale models struggle to sufficiently capture out-of-plane behavior, or that of nonconventional lay-ups.

At LoMF2, low frequency electrical and structural functionality are combined, and the structure has conductive pathways for passive conduction of electrical current. The electrical resistance of the conducting pathways must be sufficiently low, such that the voltage drop over the full network is acceptable. For example, voltage drop between the generator and distribution bus cannot be more than circa $2-4 \%$ of the rating of the cable depending on location within the EPS, and the low frequency ground plane must be equipotential [26, 27].

The maximum electrical resistance of electrical bonding between different units of electrical equipment is $2.5 \mathrm{~m} \Omega$, and any electrical bonding between the casing and the main structure of the aircraft must be $<10 \mathrm{~m} \Omega$ [27]. The conductive pathways are aligned with the plies of CFRP, in the $x-y$ plane, rather than the through thickness $z$-plane (indicated in Fig. 3). At LoMF3, electrical and structural functionality are combined but the electrical current is actively conditioned. For example, the structure has appropriate capacitive and inductive properties to carry out filtering of electrical current. Structural weakness occurs at the point where the mechanical properties of a MF component change [41]. This is of particular concern for LoMF2 and 3 where the component properties vary spatially, providing varying levels of electrical and structural functionality. Functionally graded materials (FGM) have properties which vary spatially $[42,43]$. FGM offer improved structural integrity, reducing stress concentrations, between regions of material with different properties, but the manufacture of FGM is very challenging.

One approach to overcome the challenge of FGM, may be to create plies with specific MF capability (e.g. electrical storage) in the $x-y$ direction. Electrical connections between plies may either be via cables external to the panels, or by wrapping a panel with CFRP with integrated conductive pathways where the $x-y$ direction is orientated to the $z$ direction of the original structure (as indicated in Fig. 3). A final consideration is that a combination of LoMF1-3 may be combined in a single component, depending on limitations of electrical, thermal and structural functionality, variation of the properties of the material within a single component and manufacturability.
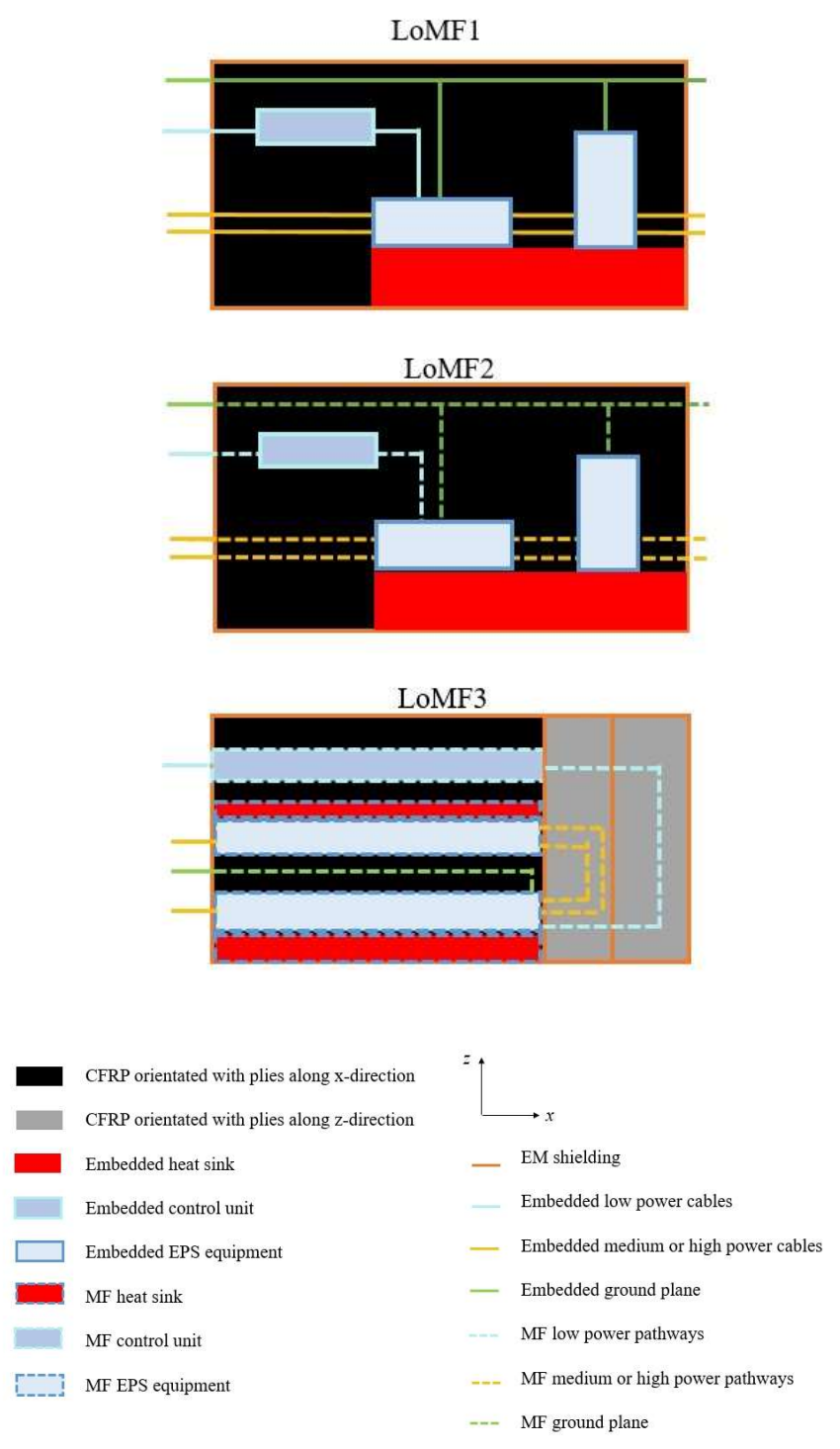

Fig. 3: Examples of the different Level of Multifunctionality (LoMF): LoMF1 (top), 2 (middle) and 3 (lower).

\section{ELECTRICAL FUNCTIONALITY CFRP LANDSCAPE}

To explore opportunities and challenges for the realization of LoMF1-3 for CFRP proposed in Section II, the relevant literature has been reviewed for each of the ten areas identified in Fig. 2. These ten areas can be divided into two broad categories of electrical functionality. The first broad category is electrical conduction, which includes passive conduction of electrical current between two points, EM shielding, the current return network and interconnections and bonding. The second broad category is the active conditioning of the electrical current.

This includes structural energy storage, electrical machine windings, filtering and switching functionality, measurement functionality and thermal management. A significant challenge to attaining all LoMF is variation of electrical functionality and material properties within a single structure, whilst maintaining mechanical integrity [41]. 
This is a pre-print of paper TTE-Reg-2021-01-0074 which was accepted for publication in IEEE Trans. On Transportation Electrification on $20^{\text {th }}$ April 2021, and as such is subject to IEEE copyright.

TABLE I

SUMMARY OF PROPERTIES OF DIFFERENT MATERIALS

\begin{tabular}{lll}
\hline \hline \multicolumn{1}{c}{ Type of Material } & \multicolumn{1}{c}{$\begin{array}{c}\text { Reported } \\
\text { electrical } \\
\text { conductivity } \\
(\mathrm{S} / \mathrm{m})\end{array}$} & $\begin{array}{c}\text { Tensile Strength (GPa) } \\
\text { (Where Available) }\end{array}$ \\
\hline Copper $\quad \begin{array}{l}5.8 \times 10^{7} \\
\quad \text { CFRP UD }\end{array}$ & $\begin{array}{l}30-40 \times 10^{3} \\
{[20,38]}\end{array}$ & 0.220 \\
$\begin{array}{l}\text { (in-fibre direction) } \\
\text { CFRP UD at 49\% VF }\end{array}$ & $50 \times 10^{3}[47]$ & - \\
with Silver interleaves & & - \\
CFRP with layers of & $14.6 \times 10^{3}[51]$ & - \\
CNT. & & - \\
Carbon-nickel-copper- & $1.05 \times 10^{6}[46]$ & - \\
veil printed onto CFRP. & & \\
CNT wire & $10 \times 10^{5}-6.7 \times$ & $0.013-1.91[56]$ \\
CuCNT wire & $10^{6}[56]$ & \\
\hline \hline
\end{tabular}

\section{A. Conduction of electrical current}

Critical to the design of conducting pathways is the electrical conductivity. As is shown in Fig. 4, the electrical conductivity

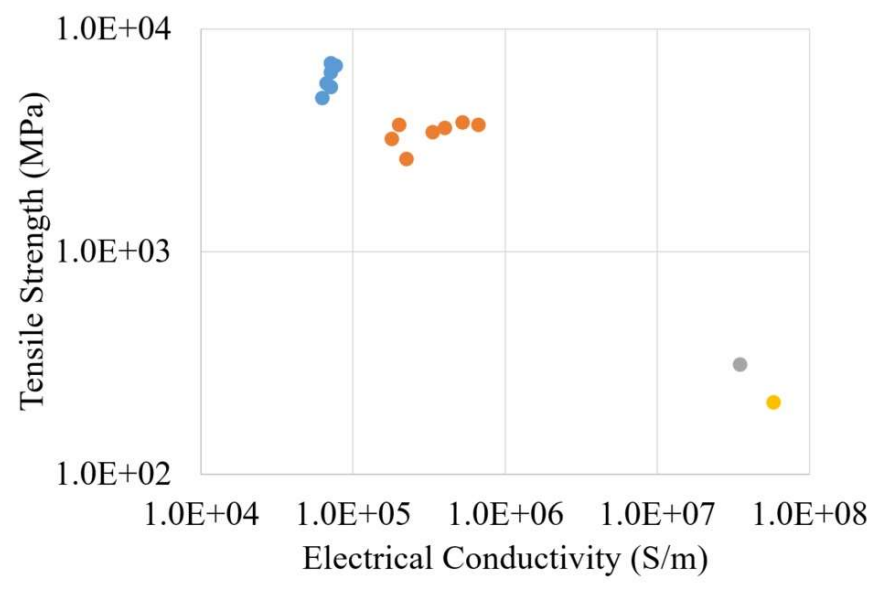

Fig. 4: Electrical conductivity against tensile strength for selected PAN (blue) and pitch (orange) carbon fibres, data from [44], aluminium (grey) and copper (yellow).

of pitch carbon fibres is an order of magnitude higher than for polyacrylonitrile (PAN) carbon fibres. Pitch $\mathrm{CF}$ electrical conductivity can be as high as $\sim 666 \mathrm{kS} / \mathrm{m}$, with maximum PAN $\mathrm{CF}$ electrical conductivity at $\sim 76 \mathrm{kS} / \mathrm{m}$ [44]. Electrical conductivity of continuous fibre CFRP layup is known to be at best $\sim 30-40 \mathrm{kS} / \mathrm{m}[20,38-40]$. However, for the fibres shown in Fig. 4, the maximum tensile strength of PAN fibres is $\sim 7000$ $\mathrm{MPa}$, whereas the maximum strength of pitch fibres is $\sim 3800$ MPa. The superior mechanical properties of PAN fibres has resulted in their use to date for aerospace structures. The thermal conductivity of PAN fibre is significantly inferior to pitch fibres: e.g. $800 \mathrm{~W} / \mathrm{mK}$ for a pitch fibre compared to 9.3 $\mathrm{W} / \mathrm{mK}$ for a PAN fibre [45]. The tensile modulus of pitch fibres is around 3 times larger than that of PAN fibres ( $300 \mathrm{GPa}$ for PAN compared to $\sim 900$ GPa pitch) [45].

Improved electrical conductivity of CFRP can be achieved by adapting the CFRP layup. A summary of the electrical conductivities of these approaches is given in Table 1. Copper foil does not physically bond well to the resin matrix, resulting in areas of structural weakness. In [46], a carbon nickel copper veil was shown to have much better porosity and better adhesion. However, whilst the electrical conductivity was high, this was used for a very low power, high frequency application. An alternative approach is interleaved silver coated veils of nylon on $\operatorname{Kevlar}^{\mathrm{TM}}$ (aramid) fibres. This was shown in [47], but in this case, it was used to improve conductivity in the through thickness and in-plane perpendicular directions.

Individual carbon nanotubes (CNTs) have electrical (conductivity, current density), thermal (conductivity) and mechanical (tensile strength) properties which are upwards of an order of magnitude better than copper [48]. Attaching CNTs to the CF in the form of 'fuzzy' fibres has been identified as a method to increase electrical conductivity [49]. Research into improving conductivity levels has focused to date on the through thickness conductivity (for lightning strike and EMI shielding applications), rather than on developing conductive pathways for sustained electrical current $[49,50]$. In the fibre direction, conductivity is reported to be improved by $330 \%$ for fuzzy CFRP [49]. An alternative approach is to place layers of CNT between CF plies in a CFRP layup. This significantly increases through thickness electrical conduction (by $\sim 10$ times), but has little effect on the in-plane conductivity of the CFRP due to the high conductivity of the CF compared to the resin matrix [51].

Manufacturing CNT cables which maintain the high electrical conductivity of individual CNTs is challenging $[52,53]$. High levels of electrical conductivity are reported in the literature [54-58] for CNT cables. However, these are still an order of magnitude lower than for copper (see Table 1). The electrical conductivity can be further improved by depositing a metallic layer, e.g. copper, around the CNTs to create a coppercarbon nanotube $(\mathrm{CuCNT})$ cable $[52,57,58]$ This results in a cable which weighs less than an equivalent pure copper cable, but has nearly comparable electrical conductivity $(47 \mathrm{MS} / \mathrm{m})$ [57] and better tensile strength. The maximum current density of the cable reported in [57] is $630 \times 10^{10} \mathrm{~A} / \mathrm{m}^{2}, 100$ times higher than copper, with a density of $5.2 \times 10^{3} \mathrm{~kg} / \mathrm{m}^{3}$, compared to $8.9 \times 10^{3} \mathrm{~kg} / \mathrm{m}^{3}$ for copper.

\section{$B$. Review of SOTA electrical functionality of CFRP}

1) Transmission and distribution of electrical current for the EPS and for low power control signals

To date LoMF 1 has been achieved for low power applications $[8,9,11]$. LoMF2 functionality is reported for high frequency, very low power applications such as antennae, waveguides and sensors, e.g. [14,59-60]. However, achieving LoMF2 for higher power applications requires understanding of the load bearing capability of conductive pathways from materials such as CuCNT. It also requires development of manufacturing methods to integrate these pathways into CFRP materials. Wider considerations, such as mismatch between coefficient of thermal expansion and mechanical integrity at the interface between different materials, must also be taken into account.

\section{2) Current return and ground plane}

CFRP has been successfully used as a high frequency ground plane for space applications [17]. For low frequency current return over composite structures, metallic grounding rails are used to form a low resistance grounding network $[16,17,61]$. Attainment of a LoMF1, with minimal cable harnesses and 
This is a pre-print of paper TTE-Reg-2021-01-0074 which was accepted for publication in IEEE Trans. On Transportation Electrification on $20^{\text {th }}$ April 2021, and as such is subject to IEEE copyright.

raceways, requires a combination of appropriate electrical grounding with fault detection and location methods. Appropriate CFRP layup and electrical bonding to ground to control the resistance added to a fault path by CFRP are also required. To date this has received limited attention in the literature $[19,20,38,39]$. A significant challenge to enabling a LoMF2 for a low frequency current return through CFRP is that a conventional CFRP plane has significant electrical resistance which makes equipotential bonding difficult to achieve [61].

\section{3) Interconnections and methods of electrical bonding}

Methods to interconnect conductive pathways and circuits in CFRP to the wider EPS are required for LoMF2 and 3. The electrical resistance associated with an interconnection must be sufficiently low both to avoid localized heating, and, when combined with other resistances in the conducting path, ensure the voltage drop over the full conducting pathway is acceptable [26]. Methods presented for electrical connection to conducting elements embedded in CFRP include copper/polyimide patches for low power applications, which have a flexibility to match CFRP [9,11], metal foils, conductive adhesives, or inductive coupling [62]. A major requirement for the development of these electrodes for an MEA EPS is to identify the main design thresholds in terms of acceptable resistance and power losses, and the limitations of the different methods of establishing an electrical contact or bond.

\section{4) Electromagnetic shielding}

The highly directional nature of the electrical conductivity of $\mathrm{CF}$ has resulted in the reporting of the suitability of continuous carbon fibres to provide EM shielding, by orientating them appropriately on the surface of a layup [31]. Unidirectional (UD) CFRP is nearly 1000 times more electrically conductive in the fibre direction than the transverse direction [31]. Hence woven layups provide better EM shielding than UD layups.

EM Shielding can be enhanced by increasing electrical conductivity [13] in the through thickness direction, via the use of carbon fillers (e.g. CNT) to the resin, fuzzy CF or a sheet of bucky paper [49,50,63-65]. Careful design of the combination of CF and CNT to create the EM shielding is required to ensure the mechanical properties of the material are not compromised [50]. Whilst MF incorporating EM properties is well developed, variation of EM shielding within a component may be required to shield between different elements of a section of EPS. Methods to achieve variation in EM shielding within a CFRP structure require further development. However, the MF options presented in the literature are more attractive than the use of a copper mesh on the outside of the CFRP, which attracts a weight penalty (around $200 \mathrm{~g} / \mathrm{m}^{2}$ [66]).

\section{5) Structural energy storage}

Two broad forms of structural energy storage have been presented in the literature: batteries and capacitors, with both supercapacitors and capacitors presented $[62,67,68,69]$. Batteries offer a higher specific energy. SOTA batteries have a specific energy of $200 \mathrm{kWh} / \mathrm{kg}$ [69]. For structural batteries, $175 \mathrm{Wh} / \mathrm{kg}$ is considered achievable [69]. To date $110 \mathrm{Wh} / \mathrm{kg}$ has been demonstrated [70]. In contrast, supercapacitors offer higher specific power, at $\sim 3 \mathrm{~kW} / \mathrm{kg}$, but a lower specific energy (3-10 Wh/kg [69]. Structural supercapacitors have been demonstrated at $\sim 165 \mathrm{~W} / \mathrm{Kg}$ and $\sim 1-10 \mathrm{mWh} / \mathrm{Kg}$ [69].

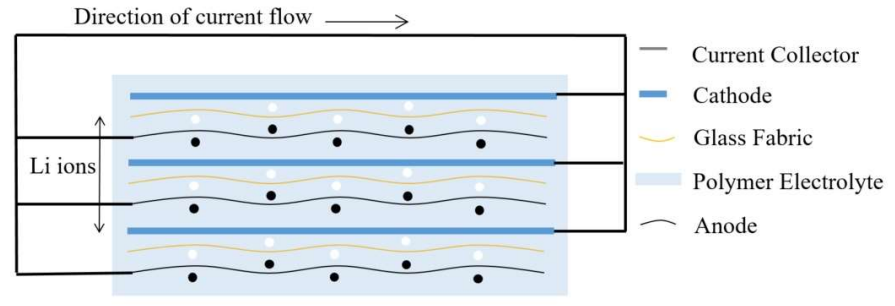

Fig. 5: Diagram of a structural battery with a laminated structure [71].

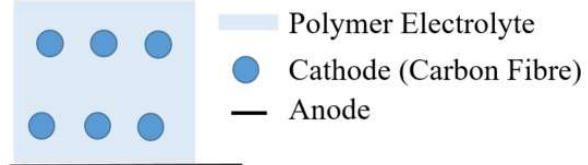

Fig. 6: Diagram of a structural battery with a fibre architecture [72].

Whilst LoMF1 has been achieved for energy storage via the bonding of thin film capacitors or batteries to the surface of CFRP [5], or batteries embedded in the honeycomb centre of a CFRP sandwich layup [9], greater performance gains can be achieved by the structure of the CFRP having dual structuralenergy storage functionality [5]. Two routes to LOMF3 for structural batteries are presented in the literature. The first is laminated batteries (Fig.5), where the negative electrode is a CFRP pre-preg and the positive electrode is carbon fibres which have a lithium-ion coating. Glass fabric acts as a separator between these electrodes, whilst ionic conductivity is enabled by the matrix system utilized. An alternative approach is the fibre architecture (Fig. 6), where the negative electrodes are made from discrete tows of carbon fibre - with a fibre coating acting as the separator - in a matrix containing lithium iron phosphate. The positive electrode is positioned at the bottom of the structure. Batteries with a fiber architecture exhibit lower ohmic losses, than laminate architectures, due to smaller separator thickness [69]. A challenge for both structural battery topologies is the physical degradation of the battery due to swelling and contracting of fibres during repeated charging and discharging. Coating fibres with CNTs or lithium fluoride nanocrystals has been demonstrated to reduce swelling of carbon fibres, thereby reducing degradation, but this is an area of on-going research [69].

Electrode development is also a challenge for supercapacitors. Supercapacitors store energy via accumulation of charge at the electrode-electrolyte interface, leading to a superior specific power compared to batteries [74]. A larger electrode surface area enables a higher electrical capacitance. However increased surface area of carbon fibre electrodes via activation, results in a lower tensile strength compared to inactivated CF $[69,74]$. The surface area of CF can be increased by treating with potassium hydroxide [75]. However, a method to enable this to be manufactured at scale has yet to be found[69]. The addition of CNT to the fibres or resin matrix offers a promising route for improved electrode performance as this improves surface area and mechanical properties [76]. A third option is the use of carbon aerogels [74].

The specific power of structural super capacitors is limited by a high electrical series resistance (ESR) [69]. The ESR can 
This is a pre-print of paper TTE-Reg-2021-01-0074 which was accepted for publication in IEEE Trans. On Transportation Electrification on $20^{\text {th }}$ April 2021, and as such is subject to IEEE copyright.

be reduced by using a poly(ethylene glycol) diglycidyl (PEGDGE) based matrix as the electrolyte. The poor compressive strength of PEGDGE can be overcome by embedding the carbon fibres in carbon aerogel [68].

A major challenge for both batteries and super-capacitors is the development of a resin matrix and electrodes which have appropriate electrical and mechanical properties, without reduction in the mechanical performance [62,69]. Mixing of immiscible polymers, where one provides structural support and the other has a high ion conductivity, is a possible solution to this problem [77]. There is conflict between good electrical performance and mechanical weakness at the interface between the carbon fibres and the resin matrix [69]. Methods to manufacture these devices with an appropriate level of repeatability and at scale need to be developed [69].

6) Composite electrical machine windings

The use of carbon fibre tows as a retaining wrap around permanent magnets in electrical machines is well established [78]. An advantage of using carbon fibre for this application is that eddy current losses are much less than for a metal alloy containment sleeve [79]. However, CFRP is magnetically inert, and a large effective airgap is produced within the machine. A method to improve the magnetic permeability of the machine via the use of iron particles in thin epoxy films or iron z-pins is presented in [80]. The disadvantage of this method is that it results in a trade between mechanical tensile strength and magnetic permeability.

The concept of replacing copper windings in an electrical machine with carbon-nanotube wire coils has been implemented in prototype PM machines rated at $30-40 \mathrm{~W}$, and $<10 \mathrm{~V}[81,82]$, with conceptual designs for machines rated at $5 \mathrm{~kW}$ [82]. Compared to copper, CNT coils reduce weight, but increase volume. To date, CNT coils in machines are monofunctional. Design of an electrical machine with electromagnetically active elements that have structural functionality (e.g. the stator of a permanent magnet synchronous machine (PMSM)) would be extremely challenging due to the reasons surrounding variation of CFRP properties within a single component as discussed earlier. Furthermore, inductive CNT coils with structural functionality are not presented in the literature. Development of MF conducting pathways and inductors would be a stepping-stone to the realization of MF machine design.

\section{7) Switching and filtering of electrical current}

Electrical current can be manipulated via switches or use of filters. Very low power, high frequency electronic switches have been successfully integrated into CFRP structures, where metallic materials have been used to form the electrical components. In [46] it is reported that a radio frequency (RF) switch has been integrated into a ten-ply structure, with electrical circuitry placed on the central ply using a carbonnickel-copper $(\mathrm{C}-\mathrm{Ni}-\mathrm{Cu})$ veil, along with the electronic chips containing the semi-conductor switch. Polyimide is reported as a substrate for an array of very low power $(\sim 100 \mu \mathrm{W})$ diodes, which are electrically connected using silver and gold conductors in [83]. However, the mechanical functionality of these systems is not presented.
High frequency, very low power multifunctional structural components with active conditioning of electrical current reported are load bearing antenna structures [14], and utilising CFRP as the ground plane for antennas is discussed in [60]. An alternative approach is presented in [59] where an amplifier for a radio frequency, very low power, application is stitched using metallic thread into the CFRP. These examples demonstrate MF systems for active conditioning of electrical current, the challenge is to develop these systems to operate at higher power levels and lower $(<\mathrm{MHz})$ frequencies. The first step towards this is appropriate, low frequency electrically conductive pathways with structural functionality in the CFRP.

Whilst MF structural electrical filters are not presented in the literature, the literature discussed above for structural capacitors and mono-functional inductive coils provides a starting point for the realization of these devices. As an alternative route to CNT coils for inductors, polymers with electromagnetic properties suitable for inductive electrical components are presented in the literature [84].

8) Measurement and sensing

The electrical properties of CFRP are sensitive to mechanical strain, temperature and damage. Methods to detect these changes in resistance are described in the literature which either use physical electrodes attached to the CFRP $[41,85,86]$, or are contactless [87]. The contactless method presented relies on the change of the signature of the response to an external EM wave. To date, these methods have been used with a focus on structural health monitoring. It may be possible to adapt these methods to detect the flow of current through a section of CFRP. At present these methods of measurement are all at LoMF1. LoMF3 would require electrodes and measurement devices to have structural functionality.

\section{9) Thermal management.}

Multifunctional structures with combined structural and thermal management have been developed to enable embedded electronics for space satellite applications in the honeycomb sandwich core of the structure $[6,8,9]$. An alternative approach is to use copper pipes bonded to the CFRP [11]. Composite heat straps have also been developed to conduct heat away from a source [11].

An area for further investigation for structural heatsink development is exploiting the ability to increase through thickness thermal conductivity by adding thermally conductive fillers to the resin matrix. A comparison of the thermal properties of different selected nanofillers is given in Table 2 . Carbonaceous based additives, such as graphene or CNT, will increase thermal and electrical properties. The addition of ceramic based additives will increase thermal, but not electrical properties. This offers the option of a thermally conducting, but electrically insulating material, which may function, for example as a heat sink. The inclusion of these fillers may improve matrix stiffness, but non-uniform dispersion of the filler in the matrix may have an adverse effect on overall stiffness of the CFRP, for example the inclusion of graphene nanoparticles presented in [89].

The temperature that CFRP can withstand is limited by the glass transition temperature $\left(T_{g}\right)$ of the resin matrix. If localized heating of the resin matrix exceeds the $T_{g}$ of the matrix, then the 
This is a pre-print of paper TTE-Reg-2021-01-0074 which was accepted for publication in IEEE Trans. On Transportation Electrification on $20^{\text {th }}$ April 2021, and as such is subject to IEEE copyright.

TABLE 2

Thermal CONDUCTIVITY OF SELECTED NANOFILLERS [88]

\begin{tabular}{llcc}
\hline \hline Filler & Category & $\begin{array}{c}\text { Thermal } \\
\text { Conductivity } \\
(\mathrm{W} / \mathrm{mK})\end{array}$ & $\begin{array}{c}\text { Electrically } \\
\text { Conductive? }\end{array}$ \\
\hline Aluminium & Metal & 234 & Yes \\
Copper & Metal & 386 & Yes \\
Silver & Metal & 427 & Yes \\
CNT & Carbon-based & $1000-4000$ & Yes \\
Carbon Fibre & Carbon-based & $300-1000$ & Yes \\
Graphene & Carbon-based & $2000-6000$ & Yes \\
Graphite & Carbon-based & $100-400$ & Yes \\
$\beta$-Silicon nitride & Ceramics & $103-200$ & No \\
Hexagonal boron & Ceramics & $185-300$ & No \\
nitride & Ceramics & $100-300$ & No \\
Aluminium nitride & Ceramics & 1000 & No \\
Diamond & Ceramics & 120 & No \\
$\beta$-Silicon carbide & Ceramics & 30 & No \\
$\alpha$-alumina & Ceramics & 270 & No \\
Beryllium oxide & C & \\
\hline \hline
\end{tabular}

resin will start to soften and cause the composite to buckle. Even as $T_{g}$ is approached, the mechanical properties of the CFRP can be severely diminished [34]. The $T_{g}$ can be increased to $300{ }^{\circ} \mathrm{C}$ by using phenollic triazine based resins (blended with a liquid cyanate ester to control the viscosity) [90].

Examples of exploitation of Joule heating during electrical conduction for light-weight de-icing capability on aircraft include using pitch based $\mathrm{CF}$ to conduct electrical current [91,92], with layers of glass fibre (GF) providing electrical isolation, or using glass fibre coated with graphene [93]. Compared to heated metal foils, these CF-based heaters perform better with better conformation to the irregular shape of the area to be heated, more uniform heating, durability and physical bonding to the rest of the structure. However combined structural and electrical-thermal functionality of the heating elements is not discussed.

A significant challenge is the mismatch of the coefficient of thermal expansion (CTE) of different materials. This results in mechanical stress within the structure, and hence is of considerable concern [94]. Dispersion of CNTs in the matrix have been shown to reduce the CTE of CFRP by $30 \%$. However, this must be traded against a decrease on tensile strength of up to $20 \%$ [95]. An alternative method to adapting the CTE presented involves using a nickel-based alloy [92].

\section{Design Space for Combined Electrical AND MECHANICAL FUNCTIONALITY}

\section{A. Identification of the design space}

Section III has identified that initial activity is reported in the literature for encasing sections of the EPS in composite materials to achieve LoMF1 defined in Section II. Whilst progress towards LoMF2 and 3 has been identified, development at these LoMF is underpinned by the development of electrically conductive pathways in CFRP which also provide structural functionality. This design space requires significant exploration and identification of a number of interdependent design thresholds and design trades. For example: the maximum current carrying capacity of a conductor is closely linked to the geometrical shape of the conductor and the thermal environment; the acceptable Joule heating of a layup is interdependent on choice of resin and external cooling; the design of a conductive pathway and the impact this may have on the mechanical functionality. Design thresholds may be identified via a mixture of experimental and theoretical methods.

A critical value for the conduction of electrical current through a conducting pathway in CFRP is the amount of power which can be dissipated through the CFRP due to Joule heating,

$$
P_{C F R P}=I_{\text {pathway }}^{2} R_{T} \quad(1),
$$

where $\mathrm{P}_{\mathrm{CFRP}}$ is the electrical power dissipated in the CFRP, $I_{\text {pathway }}(A)$ is the current conducted through the CFRP, without the temperature of the structure reaching the threshold temperature for thermal degradation. This threshold power level $\left(P_{\text {threshold }}\right)$ will vary depending on the interdependent design factors listed above. If the value for $P_{\text {threshold }}$ for a particular layup, geometry of conducting pathway and set of environmental conditions is identified, then from this target electrical conductivity for the conducting pathway can be identified to control the value $R_{T}$. However, the design process is complex as the impact of adapting the electrical properties of the conducting pathway on thermal and mechanical properties must also be investigated.

\section{B. Example identification of electrical conductivity} requirements for $U D\left[0^{\circ}\right] C F R P$

\section{1) Experimental based estimation of $P_{\text {threshold }}$}

In order to identify $P_{\text {threshold }}$ for an example case study, electrical current was injected through unidirectional (UD) $\left[0^{\circ}\right]$ IM7/8552 following the same method as described in [20]. The value of $R_{T}(\Omega)$ is the lumped resistance of the through thickness $\left(R_{z}\right)$ and fibre direction $\left(R_{x}\right)$ resistances, as described in [20]. In this case $R_{T}$ is dominated by $R_{x}$, as the outer layer of resin has been removed from the sample of CFRP. The power dissipated in $R_{T}$ is calculated using (1). Combined contact resistance at the point of entry and exit was minimized, as described in [20], and did not impact results. From previous work by the authors [96], it is known that the pathway taken through the CFRP is 1.2 plies deep and $2 \mathrm{~cm}$ wide.

By applying a range of voltages from 2.5 to $4 \mathrm{~V}$ across CFRP, the results presented in Fig. 7, indicate that if the final, steady state power dissipated in the CFRP is kept at or below $\sim 18 \mathrm{~W}$, then the localized temperature of the CFRP remains below $T_{g}$, and well below $T_{d .}$. For the IM7/8552 matrix, $T_{g}$. is $200{ }^{\circ} \mathrm{C}$ [35]. Hence $P_{\text {threshold }}$, for this layup of CFRP in laboratory conditions described in [20], and a horizontal, conducting pathway through the top 1.2 plies of CFRP over a width of $2 \mathrm{~cm}$, is identified as $18 \mathrm{~W}$.

2) Estimation of electrical conductivity requirements

The electrical resistance of the electrical pathway must be low enough that $P_{\text {threshold }}$ is not exceeded for a given current level. It must also ensure that the voltage drop across the pathway is within acceptable limits, as determined by the industry standards.

A section of network rated at $28 \mathrm{~V}_{\mathrm{DC}}$, carrying a current of $10 \mathrm{~A}$, was considered. This represents a section of the $28 \mathrm{VDC}$ 
This is a pre-print of paper TTE-Reg-2021-01-0074 which was accepted for publication in IEEE Trans. On Transportation Electrification on $20^{\text {th }}$ April 2021, and as such is subject to IEEE copyright.

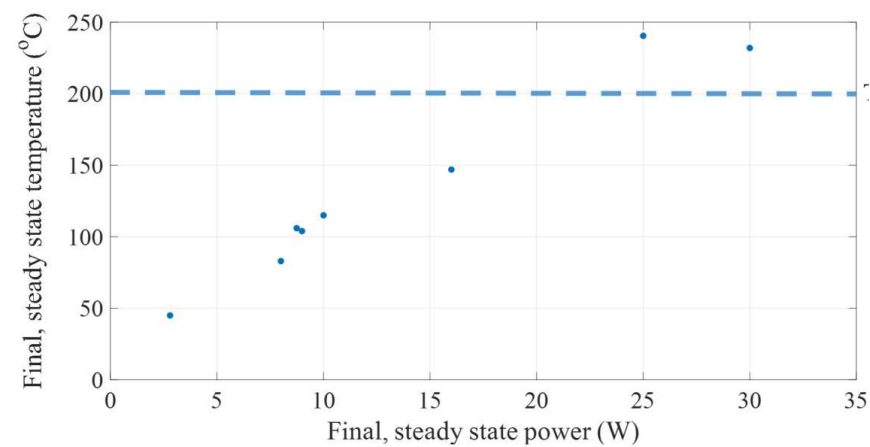

Fig. 7: Identification of $P_{\text {threshold }}$ for samples of IM7 8552 UD [ $\left[0^{\circ}\right]$, with $T_{g}$ shown by the blue dashed line.

network for the MEA (Fig 2.). The acceptable voltage drop was set to be $2 \%$ and $4 \%$, based on the standards presented in Section III. The target electrical resistance is the lower value calculated from (1) based on the threshold power, or the acceptable voltage drop for a given current. For this particular case, the maximum acceptable electrical resistance was set by the maximum allowable voltage drop.

From the target value of electrical resistance, target electrical conductivity, $\sigma_{\text {target }}(\mathrm{S} / \mathrm{m})$ is calculated using

$$
\sigma_{\text {target }}=\frac{l}{A R_{\text {target }}}
$$

where $R_{\text {target }}(\Omega)$ is the resistance of a conducting pathway, $l(m)$ is the length of the conducting pathway, and $A\left(\mathrm{~m}^{2}\right)$ is the crosssectional area of the conducting pathway. The cross-sectional conducting area was set to be $20 \times 0.15 \mathrm{~mm}$, corresponding to the cross-sectional conducting area of the CFRP from the experiments used to determine $P_{\text {threshold }}$. $0.15 \mathrm{~mm}$ corresponds to approximately 1.2 plies of UD $\left[0^{\circ}\right]$ CFRP [20]. This gives a cross-sectional conducting area of $3 \mathrm{~mm}^{2}$. Fig. 8 indicates the required conductivity for these pathways with variation in the maximum allowable voltage drop and conducted current. The conductivity required is significantly above that of UD $\left[0^{\circ}\right]$ CFRP $(30 \mathrm{kS} / \mathrm{m})$. For several cases the conductivity of CNT wire is acceptable. However, the mechanical load bearing capability of a CNT conducting pathway in a CFRP panel requires further investigation. For all of the cases the conductivity of $\mathrm{CuCNT}$ or $\mathrm{Cu}$ wire is acceptable.

However, further research is required to understand the impact of changing the conduction path cross-sectional area, shape of the conducting path, panel layup (orientation of fibre and resin choice), external environmental conditions (e.g. cooling mechanism) on both conductivity, and maximum current density requirements. Further, the impact on mechanical integrity, and the ability of the conducting pathway to take mechanical load requires further exploration.

It must also be considered that the electrical pathways require electrical bonding to external cables. In accordance with existing standards, these bonds can have a maximum resistance of $2.5 \mathrm{~m} \Omega$ [27]. For MF structural materials, this resistance may require revision to ensure that local joule heating does not exceed the power and voltage drop thresholds identified above.

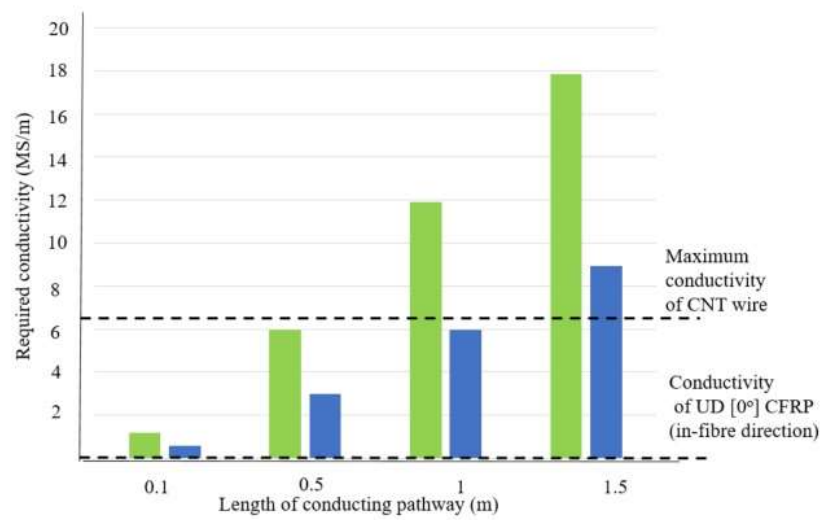

Fig. 8: Required conductivity to meet target resistance for $28 \mathrm{Vdc}$, where green is $2 \%$ voltage drop and blue is $4 \%$ voltage drop.

\section{Interdependencies between EPS and CFRP design spaces}

1) $\mathrm{LoMF} 1$

At LoMF1, the approach to fault management and grounding topology is closely interdependent with CFRP design, due to the impact that all three of these elements have on the electrical fault response of the EPS. At LoMF1 the low frequency ground plane does not have structural functionality and electrical current will only flow through CFRP during fault conditions.

It may be possible to tune the electrical properties of the CFRP, in combination with wider EPS system design (e.g. grounding topology), to ensure the desired fault response is achieved. At present, aircraft EPS use a TN-C-S grounding topology with a solidly grounded neutral point [25]. Fault detection methods for TN-C-S are reliant on a high fault current. To enable fault detection via differential unit protection, the resistance added to the fault path by the CFRP would need to be tuned to be below thresholds identified in [20] Areas to pursue for this are CFRP lay-up, panel size and approach to electrically bonding the CFRP to ground. An alternative approach may be to use a high resistance grounding (HRG) topology [19], which restricts the fault current, thereby decoupling fault response from the fault path resistance. The EPS does need to be rated for the step increase in network voltage relative to ground when a first rail to ground fault occurs. Fault location, in HRG systems can be challenging, but methods are presented in the literature, e.g. [97-99].

A further consideration at LoMF1 is the layout of electrical equipment and cables within CFRP casings. There must be adequate separation and EMC shielding ( $\sim 30 \mathrm{~dB}[30])$ between cables $[100,101]$. The thermal system must ensure not only that the equipment does not overheat, but that the CFRP is not thermally degraded.

2) LoMF2 and LoMF3

The step change from LoMF1 to LoMF2 and 3 is that the CFRP conducts electrical current during normal operation of the EPS. The EPS parameters of voltage, current and frequency directly set the conduction requirements of conductive pathways in the CFRP. If the conductive pathways cannot be designed to meet the electrical and structural requirements, then either the EPS parameters must be revised, or MF CFRP is not possible for that section of network. 
This is a pre-print of paper TTE-Reg-2021-01-0074 which was accepted for publication in IEEE Trans. On Transportation Electrification on $20^{\text {th }}$ April 2021, and as such is subject to IEEE copyright.

The choice of power distribution (AC or DC) directly influences the choice of electrical machines and power electronic converter (PEC) topologies. This is interdependent with the approach to fault management strategy, as the choice of PEC, required filters and control (interdependent with choice of PEC) will impact on fault response. The PEC topology chosen may also form part of the protection system, providing fault current limiting functionality.

Choice of electrical machine topology links closely to required control units and therefore MF CFRP requirements. A WFSM requires a power electronic control unit for the wound

TABLE 3: SUMMARY OF ROADMAP FOR LOMF1 AND 2 FOR COMPONENTS WHICH CONDUCT ELECTRICAL CURRENT

\begin{tabular}{|c|c|c|c|c|}
\hline Electrical functionality & LoMF & Desired functionality & Existing functionality & Known challenges \& limitations \\
\hline $\begin{array}{l}\text { 1. Transmission and } \\
\text { Distribution of Electrical } \\
\text { Current for a Section of } \\
\text { the EPS } \\
\text { 2. Transmission of Low } \\
\text { Power Control Signals }\end{array}$ & 2 & $\begin{array}{l}\text { Robust, mechanical bonding } \\
\text { of cables directly on CFRP. } \\
\text { Electrical impedance of CFRP } \\
\text { designed for FMS. }\end{array}$ & $\begin{array}{l}\text { - CNT based materials with high } \\
\text { conductivity developed. } \\
\text { - MF structures for very low } \\
\text { power, high frequency systems. }\end{array}$ & $\begin{array}{l}\text { - Significant gaps surrounding understanding of } \\
\text { interdependencies between thermal, electrical } \\
\text { and mechanical design thresholds exist and } \\
\text { understanding of these, and conversion of these } \\
\text { into design criteria, is needed. } \\
\text { - Existing EWIS standards do not allow for } \\
\text { conduction of electrical current through CFRP, } \\
\text { and require physical separation between EPS } \\
\text { and CFRP. } \\
\text { - Existing CFRP layups do not have adequate } \\
\text { electrical conductivity to form MF electrical } \\
\text { conduction pathways. Development and design } \\
\text { of conductive pathways which have combined } \\
\text { appropriate electrical (conductivity and current } \\
\text { density) and structural functionality is required. } \\
\text { methods for CNT based cables. }\end{array}$ \\
\hline
\end{tabular}

field voltage. Fault tolerance of a PMSM can be achieved by designing the machine such that its inductance is high enough to limit the short-circuit current to the continuous rated current of the machine. Choice of electrical machine also influences the switching frequency of associated PEC, and therefore EM shielding requirements. 
This is a pre-print of paper TTE-Reg-2021-01-0074 which was accepted for publication in IEEE Trans. On Transportation Electrification on $20^{\text {th }}$ April 2021, and as such is subject to IEEE copyright.

3. Current Return Network

\& Ground Plane

4. Interconnection

Electrical Bonding

5. EMC Shielding

- Low frequency ground rails laid direct on CFRP.

- Structure forms a low frequency current return pathway and ground plane

- Electrical bonding enables appropriate fault current pathway through CFRP.

- Low impedance electrodes for

- Flexible connectors bonding electrically (copper/polyimide or nickel

conductive pathways to foil)

external EPS and equipment encased in CFRP.

- Conductive adhesives

- Use of bulky and heavy cable harnesses and raceways to prevent fault current from passing through CFRP.

1

- EM shielding integrated into CFRP structure
- Adapt electrical conductivity using $\mathrm{CF}$ arrangement or additives.
- In combination with (2), designing appropriate electrical bonding of CFRP to ground plane to prevent excessive Joule heating.

- Design of a structure with electrically conducting pathways with sufficiently low electrical resistance to form an equipotential MF ground plane, but has appropriate mechanical strength. This also requires understanding interdependent design thresholds (as identified for 1 above).

- Existing connectors only developed for low power.

- Combining electrical bonding to CFRP with design of fault current pathway and appropriate electrical resistance

- New fault detection and protection methods required to account for higher resistance fault paths through CFRP.

- Existing EWIS standards do not allow for conduction of electrical current through CFRP, and require physical separation between EPS and CFRP.

- Ensuring low resistance at connection points to avoid localised heating.

- Linking design of electrodes with design of conductive pathways through CFRP.

- Developing published methods for very low power applications to be suitable for higher power applications.

- Method to combine a CFRP layup for EM shielding with CFRP layup for other LoMF1 functionality requires investigation.

- Non-structural copper mesh. 
This is a pre-print of paper TTE-Reg-2021-01-0074 which was accepted for publication in IEEE Trans. On Transportation Electrification on $20^{\text {th }}$ April 2021, and as such is subject to IEEE copyright.

2

\author{
- Spatial variation of EM
}

shielding in CFRP structure.
As above.
- Methods to vary the EM shielding level within

a CFRP structure, to enable shielding around

components as appropriate, requires

development.

TABLE 4: SUMMARY OF ROAD MAP FOR LOMF1 AND 3 FOR COMPONENTS WHICH ACTIVELY CONDITION ELECTRICAL CURRENT

\begin{tabular}{|c|c|c|c|c|}
\hline Electrical functionality & "LoMF & Desired functionality & Existing functionality & Known challenges \& limitations \\
\hline 6. Energy Storage & 1 & - Embedded energy storage & $\begin{array}{l}\text { - Bonding thin film capacitors to CFRP } \\
\text { - Embedding capacitors in honeycomb } \\
\text { structure }\end{array}$ & $\begin{array}{l}\text { Development of existing technologies from } \\
\text { low to high power applications }\end{array}$ \\
\hline & 3 & - Structural energy storage & $\begin{array}{l}\text { - Batteries:25 Wh/kg [70] } \\
\text { - Super-capacitors: } 3-10 \mathrm{~kW} / \mathrm{h}, 3 \\
\mathrm{~kW} / \mathrm{kg}[69] \\
\text { - Capacitors: } 90 \mathrm{~W} / \mathrm{kg} \text { [102] }\end{array}$ & $\begin{array}{l}\text { - A stepping stone to all energy storage is the } \\
\text { use of smaller, structural energy storage } \\
\text { combined with conventional energy storage. } \\
\text { - Methods for the design and manufacture of } \\
\text { FGM. } \\
\text { - Conflict between electrical and mechanical } \\
\text { properties of the resin. } \\
\text { - Poor energy density and maintaining energy } \\
\text { storage capacity over multiple cycles } \\
\text { (specific to capacitors and super-capacitors). } \\
\text { - High series resistance for super-capacitors }\end{array}$ \\
\hline 7. Electrical Machines & 1 & $\begin{array}{l}\text { Electrical machine with } \\
\text { CFRP casing. }\end{array}$ & - None at present & $\begin{array}{l}\text { - Underpinned by methods for integration of } \\
\text { cables, shielding and accessories at LoMF1 } \\
\text { (Table 2). } \\
\text { - Identification of methods for improving the } \\
\text { magnetic properties of CFRP containment } \\
\text { sleeves, whilst minimising the need to trade } \\
\text { between magnetic and mechanical } \\
\text { properties. }\end{array}$ \\
\hline & 3 & $\begin{array}{l}\text { - Structural electrical } \\
\text { machines (stator) }\end{array}$ & - Low power, machine windings & $\begin{array}{l}\text { Methods for the design and manufacture of } \\
\text { FGM. } \\
\text { Designing a system with appropriate } \\
\text { structural integrity, electrical and magnetic } \\
\text { properties, which has coils in the structure } \\
\text { with rotating centre. }\end{array}$ \\
\hline
\end{tabular}


This is a pre-print of paper TTE-Reg-2021-01-0074 which was accepted for publication in IEEE Trans. On Transportation Electrification on $20^{\text {th }}$ April 2021, and as such is subject to IEEE copyright.

\section{Switching \& filtering}

9. Measurement \& Sensing

\section{- Power electronics and filters} with CFRP casing.

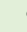

Low power, devices on flexible circuit boards with flexible connectors.

3

- Structural filters and power

- Inductive coils developed for electronics electrical machines.

- Structural capacitors

- High frequency, low power switches developed

- Embedded

measurement

- Contactless methods

devices

- Embedded electrodes

3

$$
\text { - Structural }
$$$$
\text { measurement }
$$

- Strain measurement based devices piezoresitivity.
- Extension of existing methods to high power due to thermal challenges.

- Underpinned by methods for integration of cables, shielding and accessories at LoMF1 (Table 2).

- Methods for the design and manufacture of FGM.

- Development of solid state switches at $\mathrm{kHz}$ frequencies and below.

- Translation of structural capacitors and CF based inductors to structural filters.

- Methods for the design and manufacture of FGM.

- The translation of structural health monitoring methods to electrical metrology applications is required.

- Methods for the design and manufacture of FGM.

- Whether piezoresistive methods can support measurement of electrical properties is unknown.

- Development of embedded electrodes (e.g. [87]) which have structural functionality is required.

- Limited availability of macroscale, thermal models of CFRP.

- Integration of heat management components and maintaining structural integrity.

- Mismatch between CTE of different materials.

- Extension of existing methods to higher powers

- Methods for the design and manufacture of FGM.

- Methods published limited to CFRP with honeycomb sandwich core. 
This is a pre-print of paper TTE-Reg-2021-01-0074 which was accepted for publication in IEEE Trans. On Transportation Electrification on $20^{\text {th }}$ April 2021, and as such is subject to IEEE copyright.

TABLE 5: SUMmary OF ESTIMATED TimesCALES For DEVELOPMENT OF MF CFRP COMPONENTS AT LOMF $1-3$.

\begin{tabular}{|c|c|c|c|c|c|c|c|c|c|c|c|c|c|}
\hline \multirow[t]{2}{*}{ Electrical Functionality } & \multirow[t]{2}{*}{ LoMF } & \multirow[t]{2}{*}{ Existing TRL } & & \multicolumn{10}{|c|}{ Estimated time to high TRL (Years) } \\
\hline & & & 0 & 1 & 2 & 3 & 4 & 5 & 6 & 7 & 8 & 9 & $10+$ \\
\hline \multirow{2}{*}{$\begin{array}{l}\text { 1. Transmission and Distribution of } \\
\text { Electrical Current. }\end{array}$} & 1 & Low & & & & & & & & & & & \\
\hline & 2 & Low & & & & & & & & & & & \\
\hline \multirow{2}{*}{$\begin{array}{l}\text { 2. Transmission of Low Power } \\
\text { Control Signals }\end{array}$} & 1 & High & & & & & & & & & & & \\
\hline & 2 & Low & & & & & & & & & & & \\
\hline \multirow{2}{*}{$\begin{array}{l}\text { 3. Current Return Network \& } \\
\text { Ground Plane }\end{array}$} & 1 & Medium & & & & & & & & & & & \\
\hline & 2 & Low & & & & & & & & & & & \\
\hline \multirow{2}{*}{$\begin{array}{l}\text { 4. Interconnection \& Electrical } \\
\text { Bonding }\end{array}$} & 1 & Low /Medium & & & & & & & & & & & \\
\hline & 2 & Low & & & & & & & & & & & \\
\hline \multirow[t]{2}{*}{ 5.EMC Shielding } & 1 & Medium/High & & & & & & & & & & & \\
\hline & 2 & Medium & & & & & & & & & & & \\
\hline \multirow[t]{3}{*}{ 6. Energy Storage } & 1 (Low Power) & Medium/High & & & & & & & & & & & \\
\hline & 1 (Higher power) & Low & & & & & & & & & & & \\
\hline & 3 & Low/Medium & & & & & & & & & & & \\
\hline \multirow[t]{2}{*}{ 7. Electrical Machines } & 1 & Low & & & & & & & & & & & \\
\hline & 3 & Low & & & & & & & & & & & \\
\hline \multirow[t]{3}{*}{ 8. Switching \& Filtering } & 1 (Very low power) & High & & & & & & & & & & & \\
\hline & 1 (Higher powers) & Low & & & & & & & & & & & \\
\hline & 3 & Low & & & & & & & & & & & \\
\hline \multirow[t]{2}{*}{ 9. Measurement \& Sensing } & 1 & Medium & & & & & & & & & & & \\
\hline & 3 & Low & & & & & & & & & & & \\
\hline \multirow[t]{2}{*}{ 10.Thermal Management } & 1 & Medium & & & & & & & & & & & \\
\hline & 3 & Low & & & & & & & & & & & \\
\hline
\end{tabular}

Therefore, at LoMF2 and 3, the design space includes the requirements of the EPS and the limitations of the MF CFRP, both in terms of electrical functionality but also (from Section II) in terms of mechanical integrity and manufacturability.

Finally, at LoMF2, the low frequency ground plane has structural functionality. This ground plane must meet the standards set out in Section II, requiring design and manufacture of CFRP with pathways at an appropriate electrical conductivity. The trend for increased use of DC proposed for future aircraft EPS increases the complexity of maintaining isolation between AC and DC grounds. In Section II the structural challenges of variation of properties in a CFRP structure are discussed. Thus, whether multiple, isolated ground paths can be included in a single CFRP structure requires future investigation. Galvanic isolation may be 
possible via appropriate EPS design. For example, galvanic isolation of AC and DC may be achieved via choice of PEC.

\section{ROADMAP FOR THE REALIZATION OF MF SYSTEMS}

Tables 3 and 4 combine the findings and observations from Sections II and III, to provide a road map for the development of MF structures. Table 5 is an informed estimation, by the authors, of the time required to develop MF structures, based on evidence for SOTA MF structures, presented in Section III. The numbering corresponds to the areas outlined in Section II. LoMF1 and 2 are presented for devices

which carry out conduction of electrical current (these are summarized in Table 3). LoMF1 and 3 are presented for devices which carry actively condition the electrical current in Table 4. Some functionality at LoMF2, for example electrodes and conductive pathways, will be required to enable realization of active functionality at LoMF3.

By inspection of Table 3, a significant challenge is the low maturity of MF systems, especially at low frequencies and above 'low power'. This is compounded firstly, by a lack of macroscale thermal and electrical models of CFRP, which underpin the design of MF systems at all LoMF. A second major challenge is manufacturing. If a structural, electrically conductive pathway is integrated into a panel of CFRP, firstly methods to ensure the mechanical integrity of that panel, and methods to manufacture that panel, require significant development. However, before that stage is reached, a conductive pathway with structural functionality is required. A major challenge for the design of MF systems and components, is development for high power levels. A route to designing these systems may be to start with lower power elements of the system and to then understand how these concepts can be extrapolated to higher electrical power ratings.

From inspection of Tables 3 and 4, it is clear there is significant interdependency between the development of all areas of functionality (electrical, thermal, structural). Appropriate electrical conduction, including methods to guide electrical current through CFRP (both fault current and transmission, and distribution and control signals) underpin the development of MF systems for active functionality (for example filters or energy storage). In turn, the development of these MF electrically conductive pathways is underpinned by macroscale (component scale) electrical, thermal and mechanical models.

Therefore, in order to develop MF components, first the design space in Section III must be explored further in combination with existing knowledge and functionality of the electrical conduction of CFRP, to develop methods to control the electrical pathway through CFRP to have appropriate electrical (fault response at LoMF1, distribution network or transmission of control signals at LoMF2) and structural functionality. An output of this will be the development of a suite of electrical and thermal models of CFRP, to subsequently underpin the development of appropriate layups, bonding to ground and EPS designs. Methods to develop electrically conductive pathways with structural functionality require significant development. Combined with research into manufacturing methods and bonding methods, this enables development of conductive pathways at LoMF2. This includes development of a low frequency structural ground plane. This body of work then provides a platform for LoMF3 functionality.

The most developed structural technology presented in the literature is structural energy storage, and longer term, this offers the most promising route to realize a MF component for an MEA at LoMF3. However, aside from the challenges of developing structural energy storage with the required power density and overcoming conflict between electrical and structural design elements, the integration of energy storage into a MF component with other electrical functionality is a major challenge. A developmental stepping stone could be the development of hybrid structural energy storage systems, where structural energy storage units with lower levels of energy capacity are combined with larger, non-structural energy storage components within an EPS.

FGM is the major challenge to the development of systems at all LoMF, due to the required variation of electrical properties spatially through the component. How much variation in material properties is possible in a single structural component is a significant research challenge and requires further attention. The challenge of FGM may require systems to be decomposed into several, discrete structural components.

The pathway for the development of components with LoMF $1-3$ provides a basis for the estimated timeframes to reach a high technology readiness level (TRL) for the 10 different categories of MF, initially identified in Section II. Transmission of low power control signals, EMC shielding, low power energy storage, very low power switching and filtering, and thermal management systems at LoMF1, have all been shown to be at a medium to high TRL in the literature. Development of LoMF 1 at higher power levels associated with MEA electrical power systems, will take longer, due to the technical challenges outlined above. Similarly, the timeframe for development of functionality at LoMF 2 and 3, is much longer, with a need for the underpinning research to develop these technologies to be undertaken. It is expected that for all MF components, lower power solutions will develop before higher power solutions. Hence the timeframes indicated in Table 5 are wide, particularly for LoMF 2 and 3. For example LoMF 2 for Transmission and Distribution of Electrical Current, ranges from 5 to more than 10 years of development.

\section{FUtURE DiRECTIONS}

This paper has mapped out a pathway for development of MF materials with combined structural, thermal and electrical properties to enable the development of lighter weight, compact systems for future aircraft applications, both MEA and hybrid and all electric aircraft.

For the lower frequency, higher powers associated with an on-board EPS, the pathway towards MF structures is achieved via the identification of different LoMF, and the associated challenges, thresholds and limitations for each. Significant challenges include the research unknowns surrounding limitations of developing MF CFRP with high levels of electrical conductivity (e.g. CuCNT conductors with MF capability), and manufacturability of MF components, in particular FGM. The conflict between mechanical and electrical properties is a generic challenge to the development of MF components. 

Electrification on $20^{\text {th }}$ April 2021, and as such is subject to IEEE copyright.

It is clear that MEA EPS design and MF CFRP development cannot be treated as isolated areas of research if the performance of the full future MEA is to be optimized. While the example architecture shown in Fig. 1 has an AC based distribution system, the concepts presented in this paper are equally applicable to proposed MEA EPS architectures with a DC based distribution system, such as those presented in [22]. A major challenge is the jump from LoMF1 to LoMF 2 and 3 due to the requirement for the CFRP to have electrical and structural functionality, rather than simply encase electrical equipment and only conduct in the event of an electrical fault. The pathway to MF CFRP at LoMF2 and 3 is underpinned by development of electrically conducting pathways, with mechanical functionality, through CFRP. This underpins the design of conducting pathways at LoMF3. The development of this design space is co-dependent on electrical system design parameters, in turn driven by required electrical systems functionality and capability of existing technologies.

MF CFRP has the potential to be a game changing enabler for the proposed move to hybrid and all electric aircraft, where multi-megawatt power systems and CFRP structures are proposed. Significant increases to power and energy density of components is considered a major enabler for the realization of the full spectrum of these aircraft, from all-electric urban air taxis rated at $\sim 200 \mathrm{~kW}$, to hybrid large transport aircraft rated at $60 \mathrm{MW}$. By way of an example, the target electrical power density of power electronics ranges from $3 \mathrm{~kW} / \mathrm{kg}$ for an urban air taxi to $25 \mathrm{~kW} / \mathrm{kg}$ for a large hybrid electric aircraft in 2035 [103]. MF CFRP has strong potential to support the required increase in system power and energy density. However, to achieve this, and overcome the limitations of extrapolation of design concepts from lower rated power, voltage and energy levels systems, new underpinning research areas outlined in this paper require significant further investigation to achieve the next generation of aircraft components with inherent electrical and structural multifunctionality.

\section{REFERENCES}

1. B. Sarlioglu and C.T. Morris, "More electric aircraft: review, challenges, and oppportunities for commercial transport aircraft", IEEE Trans. on Transportation Electrification, vol. 1, no.1, pp.54-65, 2015.

2. R. Jansen et al, "Overview of NASA electrified aircraft propulsion research for large subsonic transports", AIAA/SAE/ASEE Joint Propulsion Conference, 2017.

3. "Boeing 787 from the ground up", Aero Magazine, Boeing, qtr_4, Chapter 4, 2006, [online], Available: https://www.boeing.com/commercial/aeromagazine/srticles/qtr_04_06/a rticle_04_2.html

4. M. Marino and R. Sabatini, "Advanced lightweight aircraft design configurations for green operations", Practical Responses to Climate Change Conference, Engineers Australia, 2014.

5. T.J. Adam et al, "Multifunctional composite for future energy storage in aerospace structures", Energies, vol.11, article number 335, 2018.

6. K.K, Sairajan, G.S. Aglietti and K.M. Mani, "A review of multifunctional structure technology for aerospace applications", Acta Astronica, vol. 120 , pp. $30-42,2016$.

7. A Lendlein and R S Trask "Multifunctional materials: concepts, functionstructure relationships, knowledge-based design, translational materials research" Multifunctional Materials, vol.1, no. 1, 2018.

8. T.S. Jang et al, "Development of multi-functional composite structures with embedded electronics for space application", Acta Astronica, vol. 68, pp. 240-252, 2011.

9. D. Lv et al, "The application of multifunctional structure in space transportation system", IEEE Transportation Electrification Conference and Expo, 2017.
10. J. Marcos, "Multifunctional Structures, MULFUN", AST4-CT-2004516089 Final report, 2008, [online], Available https://cordis.europa.eu/project/id/516089/reporting

11. D.M. Barnett and S.P. Rawal, "Multifunctional structures technology experiment on Deep Space 1 mission", IEEE AES Systems Magazine, vol. 14, issue 1, pp.13-18, 1999.

12. M. de Rosa et al, "EMC Impact of Advanced Carbon Fiber/Carbon Nanotube Reinforced Composites for Next-Generation Aerospace Applications", IEEE trans. on Electromagnetic Capability, vol. 50, no. 3, pp. 556-563, 2008.

13. C.J. Von Klemperer and D. Maharaj, "Composite electromagnetic interference shielding materials for aerospace applications", Composite Structures, vol. 91, issue 5, pp. 467 -472, 2009.

14. A. Galehdar et al, "Capacitively fed cavity-backed slot antenna in carbonfiber composite panels", IEEE Antennas and Wireless Propagation Letters, Vol.11, pp. 1028-1031, 2012.

15. T. Shah et al, "Carbon nanostructures for electromagnetic shielding and lightning strike protection applications in sircraft", ESA Workshop on Aerospace, 2012.

16. M. Leininger et al, "Advanced grounding methods in the presence of carbon fibre reinforced plastic structures", Proc. ESA Workshop on Aircraft EMC, 2012.

17. M. Nicoletto, D. Boschetti and P. Savi, "High speed digital lines routed on non-metallic spacecraft structures", International Symposium on Electromagnetic Compatibility, 2014.

18. C.D. Nikolopoulos et al, "Verification of radiated emissions modeling for spacewire/LVDS links routed on CFRP ground", IEEE Trans. on Aerospace and Electronic Systems, vol. 56, no.1, pp. 393-402, 2020.

19. C.E. Jones et al, "Grounding topologies for resilient, integrated composite electrical power systems for future aircraft applications", AIAA/IEEE Electric Aircraft Technologies Symposium, 2019.

20. C.E. Jones et al, "Electrical and thermal effects of fault currents in aircraft electrical power systems with composite aerostructures", IEEE Trans. On Transportation Electrification, vol. 4, issue 3, pp. 660-670, 2018.

21. G. Buticci et al, "On-board microgrids for the more electric aircraft technology Review”, IEEE trans. on Industrial Electronics, vol. 66, no.7, pp. 5588-5599, 2019.

22. J. Chen, C. Wang and J. Chen, "Investigation on the selection of electric power system architecture for more electric aircraft", IEEE Trans. on Transportation Electrification, vol. 4, no. 2, pp. 563-576, 2018.

23. M. Tariq et al, "Aircraft batteries: current trend towards more electric aircraft", IET Electrical Systems in Transportation, vol.7, no.2, pp. 93103, 2017.

24. A. Nawawi et al, "Design and demonstration of high power density inverter for aircraft applications", IEEE Trans. on Industry Applications, vol. 53, issue 2, pp. $1168-1176,2017$.

25. T. Schroter and D. Schulz, "The electrical aircraft network - benefits and drawbacks of modifications", IEEE trans. on Aerospace and Electronic Systems, vol.49, no.1, pp. 189 -200, 2013.

26. Federal Aviation Administration, "Advisory circular 43.13-1B: Acceptable methods, techniques and practices - aircraft inspection and repair", U.S. Department of Transportation, 1998.

27. SAE Aerospace, "Aerospace Recommended Practice 1870: Aerospace systems electrical bonding and grounding for electromagnetic compatibility and safety", SAE International Group, 2012.

28. J. Chua, "Supplement to M6.11/M7.07 EWIS: Bonding and grounding network for composite structure aircraft", Temasek Polytechnic, 2018.

29. J. Dalton et al, "Rigid raft," U.S. Patent 9456472 B2, Sep. 27, 2016

30. B. Drury, "The control techniques drives and controls handbook", Institution of Engineering and Technology, $2^{\text {nd }}$ edition, 2009.

31. D.D.L. Chung and A.A. Eddib, "Effect of fiber lay-up on the electromagnetic interference shielding effectiveness of continuous carbon fiber polymer-matrix composite", Carbon, vol. 141, pp. 685-691, 2019.

32. M. H. Al-Saleh and U. Sundararaj, "A review of vapor grown carbon nanofiber/polymer conductive composites", Carbon, Vol. 47, Issue 1, pp 2-22, 2008

33. K.K. Satheesh Kumar, S. Geetha and D.C. Trivedi, "Freestanding conducting polyaniline film for the control of electromagnetic radiations", Current Applied Physics, vol. 5, issue 6, pp. 603 -608, 2005.

34. O. I. Zhupanska and R.L. Sierakowski, "Electro-thermal-mechanical coupling in carbon fiber polymer matrix composites", Acta Mechanica, vol. 218, pp. 319-332, 2011. 
35. -, "HexPly 8552 Epoxy Matrix Product Data Sheet", Hexcel, 2020, [online], available: https://www.hexcel.com/user_area/content_media/raw/HexPly_8552_eu DataSheet.pdf

36. -, "HexPly M9.1H Product Data Sheet", Hexcel, 2020, [online], available:

https://www.hexcel.com/user_area/content_media/raw/HexPly_M9.1H_ DataSheet.pdf

37. T. Ogasawara, Y. Hirano and A. Yoshimura, "Coupled thermal-electrical analysis for carbon fiber/epoxy composites exposed to simulated lightning current", Composites Part A: Applied Science and Manufacturing, vol. 41, issue 8, pp. 973 -981, 2010.

38. A. Piche, D. Andissac and I. Revel., "Dynamic electrical behaviour of a composite material during a short circuit", 10th International Symposium on Electromagnetic Compatibility (EMC Europe), 2011.

39. J. Rivenc et al, "A multiphysic approach to predict the degradation of a composite material due to current injection", $17^{\text {th }}$ European Conference on composite materials, 2016.

40. F. D. Senghor, G. Wasselynck and H.K. Bui, "Electrical conductivity tensor modelling of stratified woven-fabric carbon fiber reinforced polymer composite materials", IEEE Trans. on Magnetics, vol. 53, no. 6, 2017.

41. D.D.L. Chung, "A Review of multifunctional polymer-matrix structural composites", Composites Part B, vol. 160, pp. 644-660, 2019

42. .P. Tsotra and K. Friedrich, "Electrical and mechanical properties of functionally graded epoxy-resin/carbon fibre composites", Composites Part A: Applied Science and Manufacturing, vol. 34, issue 1, pp. 75-82, 2003.

43. E. Mueller et al, "Functionally graded materials for sensor and energy applications", Materials Science and Engineering: A, vol.362, issues 1-2, pp. 17-39, 2003

44. -,"900GPa - Worldwide Hub for composite materials", [online]. Available: https://www.900gpa.com/en?u=metric

45. M. Mlnus and S. Kumar, "The processing, properties and structure of carbon fibers", Journal of The Minerals, Metals and Materials Society, vol. 57, pp. 52-58, 2005.

46. G. Bezuik et al, "RF signal multiplexer embedded into multifunctional composite structure", IEEE Trans. On Microwave Theory and Techniques, vol. 67, no. 12, pp. 4935 - 4943, 2019.

47. M. Guo et al, "Preparation of highly electrically conductive carbon-fiber composites with high interlaminar fracture toughness by using silver plated interleaves", Composites Science and Technology, vol. 176, pp.2936, 2019.

48. H. Li et al, "Carbon nanomaterials for next generation interconnects and passives: physics, status, and prospects", IEEE trans. on Electronic Devices, vol 56, no.9, pp. $1789-1821,2009$.

49. T. R. Pozegic et al, "Low temperature growth of carbon nanotubes on carbon fibre to create a highly networked fuzzy fibre reinforced composite with superior electrical conductivity", Carbon, vol, 74, pp. 319-328, 2014.

50. S. Gong et al, "Effect of carbon nanotubes on electromagnetic interference shielding of carbon fiber reinforced polymer composites", Polymer Composites, vol. 39, issue S2, pp. E655-E663, 2018.

51. H.S. Kim and H.T. Hahn, "Graphite fiber composites interlayered with single-walled carbon nanotubes", Journal of Composite Materials, vol. 45, issue 10, pp. 1109-1120, 2011.

52. X. Zhang et al, "Understanding the mechanical and conductive properties of carbon nanotube fibers for smart electronics", Advanced Materials, vol.32, issue 5,2019

53. X. Wang et al, "High-ampacity power cables of tightly-packed and aligned carbon nanotubes", Advanced Functional Materials, vol. 24, issue 21, pp 3241-3249, 2014.

54. F. Mirri et al, "Lightweight, flexible, high performance carbon nanotube cables made by scalable flow coating", American Chemical Society Applied Materials and Interfaces, vol. 8, issue 7, pp. 4903-4910, 2016

55. C. D. Cress et al, "Carbon nanotube wires with continuous current rating exceeding 20 Amperes", Journal of Applied Physics, vol. 122, issue 2, 2017.

56. A. Lekawa-Raus et al, "Electrical properties of carbon nanotube bases fibers and their future use in electrical wiring", Advanced Functional Materials, vol. 24, issue 24, pp. 3661-3682, 2014.

57. C. Subramanian et al, "One hundred fold increase in current carrying capacity in a carbon nanotube-copper composite", Nature Communications, vol 4, article no. 2202, 2013.
58. B.Han et al, "Fabricating and strengthening the carbon nanotube/copper composite fibers with high strength and high electrical conductivity", Applied Surface Science, vol. 441, pp. 984-992, 2018.

59. TC Baum et al, "Embroidered active microwave composite preimpregnated electronics", IEEE Trans. On Microwave Theory and Techniques, vol. 64, issue 10, pp. $3175-3186,2016$.

60. G. Artner, R. Langwieser and C. Mecklen Braeuker, "Concealed CFRP vehicle chassis antenna cavity", IEEE Antennas and Wireless Propagation Letters, vol. 16, pp. 1415 - 1418, 2016.

61. G.D. Gutierrez et al, "On the design of aircraft electrical structure networks", IEEE Trans. On Electromagnetic Compatibility, vol. 58, issue 2, pp. 401-408, 2016.

62. D.D.L. Chung, "Development, design and applications of structural capacitors", Applied Energy, vol. 231, pp. 89 -101, 2018.

63. Z.J. Zhao et al, "MWCNT modified structure-conductive composite and its electromagnetic shielding behavior", Composites Part B: Engineering, vol. 130, pp.21-27, 2017.

64. M. Mishra et al, "Tunable EMI shielding effectiveness using new exotic carbon: polymer composites", Journal of Alloys and Compounds, vol. 688, part B, pp. 399-403, 2016.

65. M. Nicoletto et al, "MWCNTs Nanocompsites for Space Applications", IEEE International Symposium on Electromagnetic Compatibility, 2015.

66. -,"Shielding effectiveness of expanded metal foils (EMTs), Dexmet Corporation, 2017 [online], available: https:/www.dexmet.com

67. L.E. Asp et al, "Structural battery composites: a review", Functional Composites and Structures, vol. 1, no.4, 2019.

68. N. Shirshova et al, "Structural composite supercapacitors", Composites Part A: Applied Science and Manufacturing, vol. 46, pp. 96-107, 2013.

69. L.E. Asp and E.S. Greenhalgh, "Structural Power Composites", Composites Science and Technology, vol. 101, pp. 41-61, 2014.

70. W. Johannisson, D. Zenkert and G. Lindbergh, "Model of a structural battery and its potential for system level mass savings", Multifunctional Materials, vol. 2, no.3, 2019.

71. J.F. Snyder et al, "Multifunctional structural composite batteries", Proceedings of Society for the Advancement of Materiel and Process Engineering (SAMPE), 2006

72. T. Carlson. "Multifunctional composite materials - design, manufacture and experimental characterisation", PhD. Thesis, Luleå University of Technology, Luleå, Sweden, 2013.

73. E. Greenhalgh et al, "Recent advances in structural supercapacitors for transport applications", $20^{\text {th }}$ International Conference on Composite Materials, 2015.

74. C. González et al, "Structural composites for multifunctional applications Current challenges and future trends", Progress in Materials Science, vol. 89, pp. 194-251, 2017.

75. R. Kötz and M. Carlen, "Principles and applications of electrochemical capacitors", Electrochimica Acta, vol. 45, no. 15-16, pp. 2483 - 2498, 2000.

76. H. Qian et al, "Hierarchical composites reinforced with carbon nanotube grafted fibers: the potential assessed at the single fiber level", Chemistry of Materials, vol. 20, no. 5, pp 1862 - 1869, 2008.

77. Y.Yu et al, "Co-continuous structural electrolytes based on ionic liquid, epoxy resin and organoclay: Effects of organoclay content", Materials \& Design, vol. 104, pp. 126-133, 2016.

78. A.Binder, T. Schneider and M. Khlor, "Fixation of buried and surfacemounted magnets in high-speed permanent-magnet synchronous machines", IEEE Trans. On Industry Applications, vol. 42, issue 4, pp. 1031-1037, 2006.

79. A. S. Thomas, Z.Q. Zhu and G.W. Jewell, "Comparison of flux switching and surface mounted permanent magnet generators for aerospace applications", $5^{\text {th }}$ IET International Conference on Power Electronics, Machines and Drives, 2010.

80. L.E. Edwards et al, "Structural magnetic composites for use in electromechanical applications" $20^{\text {th }}$ International Conference on Composite Materials, 2015.

81. P. Juha et al, "Replacing copper with new carbon nanomaterials in electrical machine windings", International Review on Electrical Engineering, 2015.

82. P. Ramesh and N.C. Lenin, "High power density electrical machines for electric vehicles - comprehensive review based on material technology", IEEE trans. On Magnetics, vol. 55, no. 11, .2019.

83. Z.Guo et al, "A super stretchable organic thin film diodes network that can be embedded into carbon fiber composite materials for sensor 
network applications", Journal of Microelectromechanical Systems, vol. 25 , issue 3, pp. $524-532,2016$.

84. A. Malti et al, "Electromagnetic devices from conducting polymers", Organic Electronics, vol. 50, pp. $304-310,2017$.

85. A. Alsaadi et al, "Structural health monitoring for woven fabric CFRP laminates", Composites Part B: Engineering, vol. 174, 2019.

86. J.C. Abry et al, "In-situ monitoring of damage in CFRP laminates by means of $\mathrm{AC}$ and DC measurements". Composites Science and Technology, vol. 61, issue 6, pp. 855-864, 2001.

87. Y. Kostogorova-Beller et al, "A study on smart SansEC skin sensing for real-time monitoring of flexible structures", IEEE Sensors Journal, vol. 18, issue. 7, pp.2836 - 2844, 2018.

88. H. Chen et al, "Thermal conductivity of polymer-based composites: fundamentals and applications", Progress in Polymer Science, vol. 59, pp. 41-85, 2016.

89. E. Kandare et al, "Improving the through-thickness thermal and electrical conductivity of carbon fibre/epoxy laminates by exploiting synergy between graphene and silver nano-inclusions", Composites: Part A: Applied Science and Manufacturing, vol. 69, pp. 72-82, 2015.

90. A. Tsiamis et al, "Liquid processable, thermally stable, hydrophobic phenolic triazine resins for advanced composite applications", $A C S$ Applied Polymer Materials, vol. 1, no. 6, pp. 1458-1465, 2019.

91. N. Forintos and T. Czigany, "Multifunctional application of carbon fiber reinforced polymer composites: electrical properties of the reinforcing carbon fibers - a short review", Composites Part B: Engineering, vol. 162 , pp. $331-343,2019$.

92. F. de Rosa and A. Esposito, "Electrically heated composite leading edges for aircraft anti-icing applications", Fluid Dynamics and Materials Processing, vol.8, no. 1, pp. 107-128, 2012.

93. N. Karim et al, "Graphene-based surface heater for de-icing applications", Royal Society of Chemistry Advances, vol.8, Article no. 16815, 2018.

94. C. Zweben, "Advances in composite materials for thermal management in electronic packaging", Journal of The Minerals, Metals and Materials Society, vol. 50, pp. 47-51, 1998.

95. A. Godara et al, "Influence of carbon nanotube reinforcement on the processing the mechanical behaviour of carbon fiber/epoxy composites", Carbon, vol. 47, issue 12, pp. 2914-2923, 2009.

96. C.E.Jones et al, "Electrical model of carbon fibre reinforced polymers for the development of electrical protection systems for more-electric aircraft", $18^{\text {th }}$ European Conference on Power Electronics and Applications, 2016.

97. T. Baldwin and F. Renovich, "Analysis of fault locating signals for highimpedance grounded systems", IEEE Trans. Industry Applications, vol.38, issue. 3, pp. 810-817, 2002.

98. J. Hu et al, "Flux linkage detection based ground fault identification and system diagnosis in high-resistance grounding faults", IEEE Trans. on Industry Applications, vol. 53, No. 3, pp. 2967 -2975, 2017.

99. G. Skibinski et al, "Part II: Application guidelines for high resistance grounding of low-voltage common AC-bus and common DC-bus PWM drive systems", IEEE Trans. on Industry Applications, vol. 51, issue. 2, pp. $1385-1397,2015$.

100. -"DO 160G Environmental conditions and test procedures for airbourne equipment", RTCA, 2014.

101. Federal Aviation Administration, "AC 25.1701-1 - Certification of electrical wiring interconnection systems on transport category airplanes", December 2007

102. K.-Y. Chan et al, "A critical review on multifunctional composites as structural capacitors for energy storage", Composite Structures, vol. 188, pp. $126-142,2018$.

103. "Insight 07: Electrical power systems", Aerospace Technology Insitute, July 2018, [online], available: https://www.ati.org.uk/media/ntlocbb4/insight_07-electrical-powersystems.pdf

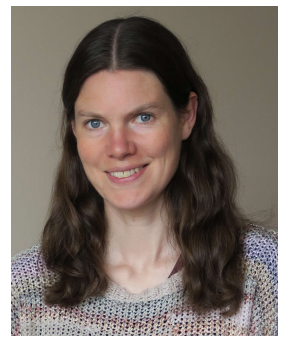

Catherine E. Jones (Member, IEEE) received the M. Eng. Degree (Hons) in electronics and electrical engineering from the University of Glasgow, Glasgow, U.K. in 2003, and the Ph.D. Degree in electrical engineering from the University of Manchester, Manchester, U.K. in 2006. She is currently a Research
Fellow with the Rolls-Royce University Technology Centre for Electrical Power Systems, Institute for Energy and Environment, University of Strathclyde, Glasgow, U.K. Her research interests include power system architectures, protection and grounding for compact electrical power systems, including hybrid-electric propulsion applications, and the integration of the electrical power system with composite structures.

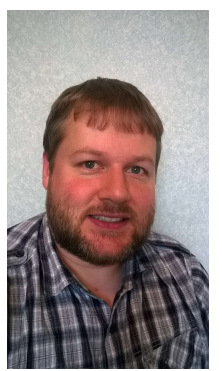

Patrick J. Norman received the B.Eng. degree (Hons.) in electrical and mechanical engineering and the Ph.D. degree in electrical engineering from the University of Strathclyde, Glasgow, U.K., in 2002 and 2009, respectively. He is currently a Reader with the Institute for Energy and Environment, University of Strathclyde. His research interests lie in the modelling and simulation, design, control, protection of aircraft secondary power offtake and distribution systems, microgrid, and shipboard power systems.

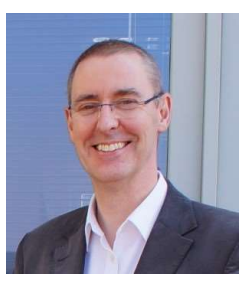

Graeme Burt (M'95) received the B.Eng. degree and Ph.D. degree from the University of Strathclyde, Glasgow, U.K., in 1988 and 1992, respectively. He is currently a Distinguished Professor of electrical power systems at the University of Strathclyde where he directs the Institute for Energy and Environment, directs the Rolls-Royce University Technology Centre in Electrical Power Systems, and is lead academic for the Power Networks Demonstration Centre (PNDC). In addition, he serves on the board of DERlab e.V., the association of distributed energy laboratories. His research interests include the areas of decentralised energy; electrification of propulsion; DC and hybrid power distribution; experimental systems validation.

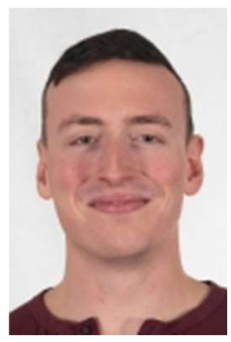

Callum Hill is a PhD student in the Bristol Composites Institute at the University of Bristol. His research focus is on the use of multifunctional composite materials to facilitate the electrification of aircraft. His work in this area involves the development of a multi-scale, multi-physics model of fibrereinforced composites.

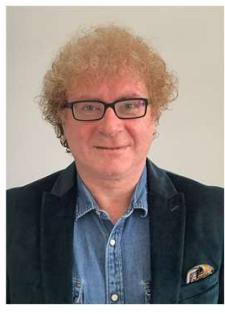

Giuliano Allegri is a Reader in Composite Structures at the University of Bristol. He is affiliated with the Department of Aerospace Engineering, the Bristol Composites Institute (ACCIS) and he is Deputy Director of the Rolls-Royce Composites University Technology Centre. He also holds a Visiting Senior Lectureship at the Department of Aeronautics of Imperial College London. Giuliano's research 
This is a pre-print of paper TTE-Reg-2021-01-0074 which was accepted for publication in IEEE Trans. On Transportation Electrification on $20^{\text {th }}$ April 2021, and as such is subject to IEEE copyright.

interest is focussed on the prediction of the mechanical performance of composite materials subject to harsh environmental conditions, with special emphasis on the characterisation and modelling of fatigue to predict the longterm durability of composite structures in aerospace, automotive and wind energy engineering.

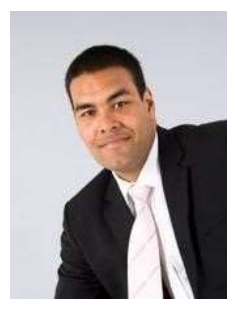

Jason M. Yon received the MEng degree in Avionic Systems Engineering in 2007 and a $\mathrm{PhD}$ in Aerospace Electrical Systems in 2012, both from the University of Bristol. He is now a Lecturer in Electromechanical Systems at the University of Bristol. His research covers a broad range of topics related to electric machines, design and manufacture and the development of novel characterization techniques for electromechanical systems.

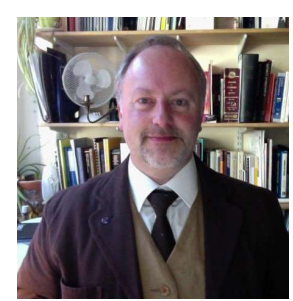

Ian Hamerton is Professor of Polymers and Composite Materials in the Bristol Composites Institute, Department of Aerospace Engineering at the University of Bristol) with over 30 years of research experience into the development of materials for advanced composites and nanocomposites. $\mathrm{He}$ is recognised internationally for work on high performance polymers (GS hindex of 34, $>6500$ citations). Ian is Deputy Director/Research Coordinator of the ACCIS and CoSEM Centres for Doctoral Training.

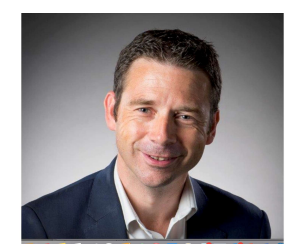

Richard S. Trask is a Professor of Advanced Materials in the Bristol Composites Institute, Department of Aerospace Engineering at the University of Bristol, with over 20 years of research experience into the development of bioinspired multifunctional composite materials and novel manufacturing techniques. To date, he has 65 publications, H-index of 36, 5075 citations and has secured $£ 14 \mathrm{M}$ of research income through EPSRC, EU FP7 Marie Curie, UK industry and UK Charities. 